SF 429

A6 B5 


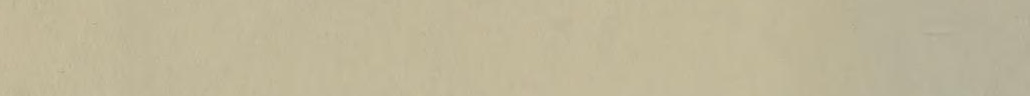




¿ Bettis, Rober L. .

Airedale Breeders'

Hand Book

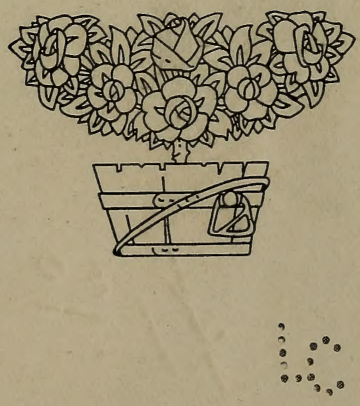

COPYRIGHTED, 1916 


$$
\begin{array}{r}
S F 429 \\
A 6 B 5
\end{array}
$$

$\varepsilon$

810

(C) Cl. 4455289

$$
\text { JAN } 251917
$$




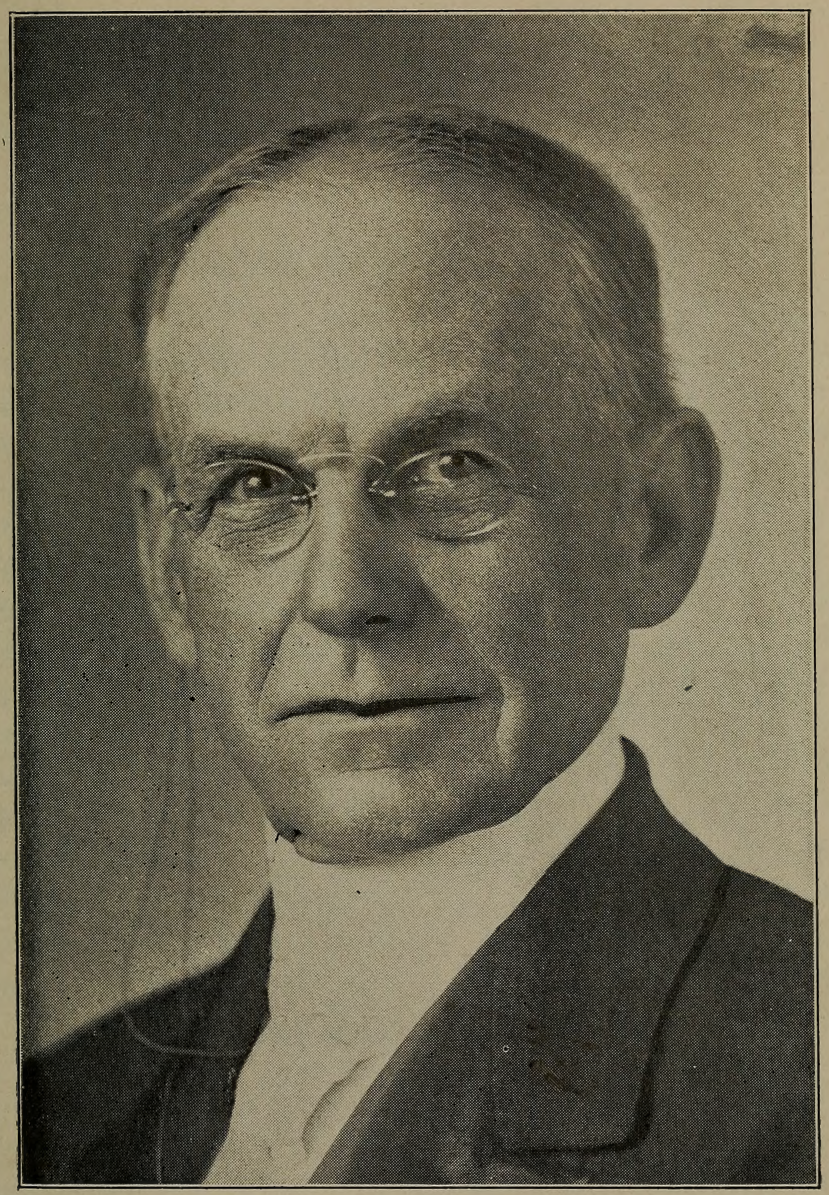

The Author. 



\section{INDEX TO CHAPTERS}

Chapter 1. Origin and Adaptability _....... Page 9

Chapter 2. Three kinds are being bred ............ 15

Chapter 3. Buying

Chapter 4. Feeding

Chapter 5. The Stud Dog.................. 27

Chapter 6. The Brood Bitch._......... 31

Chapter 7. Right Mating ............ 38

Chapter 8. Raising Puppies ....... 43

Chapter 9. Training ........ 51

Chapter 10. Kenneling . . . . 59

Chapter 11. Diseases_._._._._._. 65

Chapter 12. Color and Other Points_........ 75

Chapter 13. Showing

Chapter 14. Selling and Shipping ... _................ 84

Chapter 15. Advertising .......................... 88

Chapter 16. Miscellaneous..._._._._._. 91 


\section{Ta A}

whose constant aid; unceasing care and interest together with advice and encouragement during the years that we have been handling and breeding the Airedale; thus making this work possible, are these efforts reverently and affectionately dedicated.

The Author. 


\section{Intraùutaru}

This book is written at the suggestion of friends of the author and admirers of the Airedale; to meet a demand for information of a practical nature; and in such form that it can be had on any subject, connected with the Airedale, with as little effort as possible.

In writing, we have endeavored to use every day expressions, to be as plain and explicit as possible and to state facts just as we have found them after years of experience. In this wiriting we have tried to be honest: we have gucssed at nothing, but have tried to touch upon the different subjects as concisely as possible, and have written without fear or favor. We have not intended to injure any one in any way, our years of sportsmanship would forbid that, and if what is herein contained, will aid any one to avoid the pit-falls that the author has encountered; will assist him in caring for and enjoying man's best friend (of any breed); will better acquaint him with the most marvelous variety of the canine race that has yet been produced; will add in any way to the welfare and improvement. of this breed; or add one iota to the bettermnet of the doggy game in any particular, then will we feel fully compensated for the effort. 



\section{CHAPTER I. \\ ORIGIN AND ADAPTABILITY}

bout the middle of the nineteenth century, among a 1. sporty class of English, there sprang up a demand for a
dog that could "do anything that any other dog could
do and then lick the other dog." To produce such, sporty class of English, there sprang up a demand for a
dog that could "do anything that any other dog could
do and then lick the other dog." To produce such, sporty class of English, there sprang up a demand for a
dog that could "do anything that any other dog could
do and then lick the other dog." To produce such, Spaniels, Setter, Bedlington Terriers and perhaps other breeds No mongrel was used in the make up and there is no cold blood in them, as least in their origin.

When first produced they were called "Waterside Terrier", and were used for many purposes, including poaching. When used for this purpose it was necessary that they should not make noise and this is why some of the ones first brought to America did not give tongue when running a trail.

At this stage of their production a prominent Lord took them up, sought to make them more game, a better water dog and to improve their nose and hunting quality.

To do this the Otter Hound was used. A noble fellow this, he can handle the oldest of trails, take to the coldest water and kill Mr. Otter when he finds him.

Therefore the chief foundation for the Airedale is the Otter Hound, while many other breeds have played a minor part.

He originated in the valley (dale) of the Ayre River and obtains his name from that section.

We are told that in some kennels the Otter Hounds are muzzled at night to prevent fighting. They have very pleasant dispositions usually, but when they get started fighting are extremely vicious. Many Airedales are very similar to them in this respect.

Those who first produced Airedales were miners and workmen of similar class, whose chief sports were beer drinking, hunting various kinds of game, showing and fighting their dogs and themselves.

To these sporty fellows must be given the credit for making the greatest dog-rather breed of dogs-that has yet been produced. He is rightly called the "aristocrat of dogdom" and is surely the most cosmopolitan of them all. He is at home in guarding the parlors of a mansion; escorting mi-lady on the street, for a stroll 
in the country, a horse-back jaunt or in the limousine. As some one has said, "he is there all in a bunch". Equally so is he at home in the humblest hut and guards his master and his master's belongings with the same ardor whether he be fed with the best of foods plentifully, or is kept on short rations. Usually they are rather light eaters.

As a companion, guard and protector for children, he has no equal and many are the stories that could be told of how he has saved and rescued them when in danger by acting quickly with superior judgement. A good Airedale can act while the average person is thinking. He never tires of entertaining his charges and if he has the proper disposition will take all kinds of punishment from the child he is protecting, without harming it. We have known him to protect the child from its own parerit, when he thought the parent was going to do the youngster harm.

Many Airedales are students of human nature, at a glance can tell just what the mental condition of their master is, and many will do something to amuse the master when he feels a bit "blue", and in fact will drive the "blues" away if it can be done. Jolly dispositions predominate and they are usually ready for a romp or play. Among themselves they are the roughest of players and apparently try to see how much punishment the other will stand without "squealing." The exercise taken in this way, keeps them in condition for hunting and other tasks while other breeds would be soft.

As a hunter and fighter of big game he has no equal; and since many of the first ones brought to the States were largely used for this purpose, many persons think they are only good for the one usage. As a matter of fact, if bred right and handled right they àre equally as good for any other purpose to which a dog of the size can adapt himself.

While many of them have an excellent nose and can locate a very old track, they are not so good at trailing as the well trained hound. They are too fast and run over the trail. They want the game and not its tracks. On warm trail, the writers experience has been that they will run away from the hounds. That is if those used are of the type that have speed. When the game is overtaken it means that it is going to be killed or treed, and in very short order. 


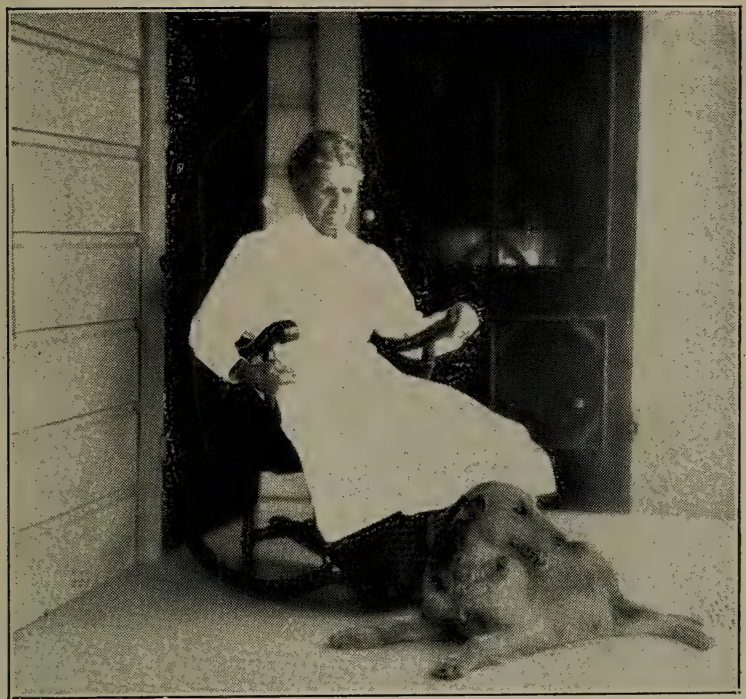

Companions.

On small game they can be fully as valuable. We have had a number of them to point quail naturally and their speed and agility when after a winged quail is marvelous As a retriever from land or water they have no superior.

They surpass as stock drivers and will not quit when the weather is hot and the task hard and hazardous. Out on the poultry ranch they are also at home. We have seen them distinguish a strange fowl of the same color as their owners' flock. They will stop all fights and aid in many ways in handling poultry. Will kill the mice and rats that infest the feed house and all skunks and marauders are sure to meet death.

On the ranch; patroling manufacturing plants; as police dogs; in the war, carrying messages, hunting and aiding the wounded and by their superior scenting and hearing, assisting the sentry, they are equally as valuable. Major Richardson, the highest authority on war dogs, says an Airedale can hear three hundred yards further than the average person. 


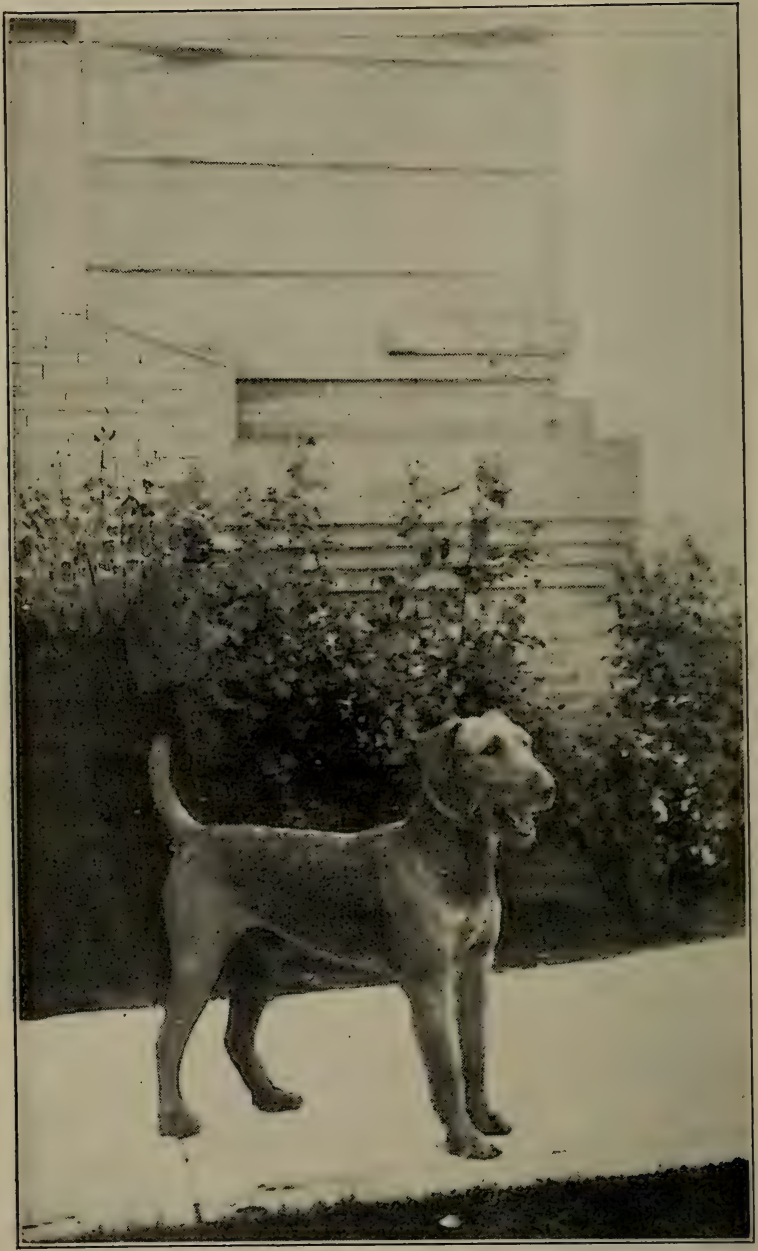

Out with the Sergeant, (Police). 
By his aristocratic bearing a good Airedale will command attention and respect anywhere and give distinction to his fortunate owner.

While most of them will meet friendly advances, except under conditions that would jeopardize them or their master's interests, they recognize but one master at a time and are called "a one man dog."

Superior judgement, self control, intensity of purpose, determination, ingenuity, strength and agility are what enables a good specimen of the breed to acquire these accomplishments and to be of such value to his owner.

While the writer has had some twenty five years of experience in breeding and training dogs of several breeds, our opinion of the Airedale, after many years of breeding, showing, hunting and otherwise educating them, is summed up in the following words. "We would not give a good Airedale for a field full of any other variety." And we have no idea of going back to any other breed. The Airedale is not a fad, he has not only made good, he has done much more. He has shown us. He has done many, many things that we never thought a dog could do. He has proven that he can more than pay his way if his master will handle him rightly and let him have an opportunity to pay for his keep and splendid interest on the investment made in his purchase. In fact the Airedale, that only a few years ago was seen here and there, in another few years will be seen every where; will be much better understood and the good ones will be even of greater value to their proud owners.

Some one has written - and well written - that if all other varieties were extinct the Airedale would replace each of them. If you, $\mathrm{Mr}$. Reader, do not think this is true, get a good one and he will "show you."

By no means do we mean to cast any reflection on any other breeds, many good ones there are, but after close intimacy, our hat is off to the noblest and truest of them all, the sturdy one from Yorkshire. 


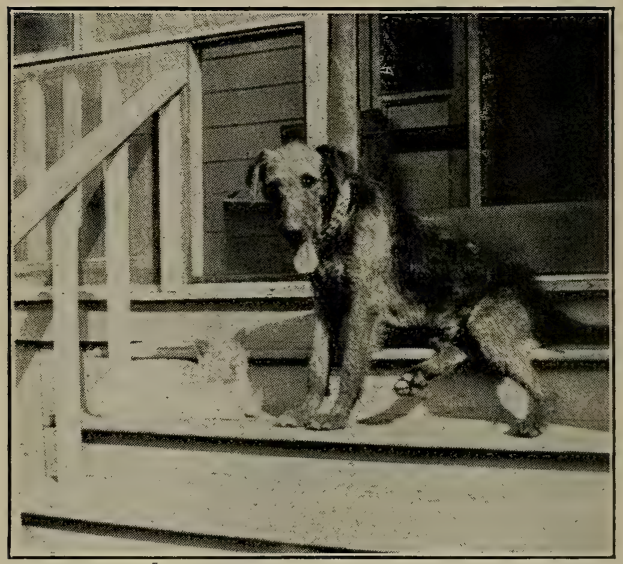

Hy Born Defiance and "Tom".

In the above cut is shown the young Airedale Hy-Born Defiance and his "pal," the white cat. Two years ago when Mr. F. D. Maginnis, So. Dos Palos, Cal., purchased the dog, then a puppy of two months, the cat took an interest in him and the puppy slept with him for some two months and never seemed to forget the kindness shown him. When he became a dog and "Tom" would go out o'nights and return the next morning, badly disfigured the dog would take him between his paws and thoroughly dress his wounds, not quitting till "Tom" was as white and clean as he could be gotten. "Tom" soon learned to hunt up his friend, when he had been "out for the evening," and would lie patiently while he was being put in condition.

Hy-Born Defiance was recently killed by a train and the loss was very keenly felt, as he had many other accomplishments. 


\section{CHAPTER II. \\ THREE KINDS ARE BEING BRED}

Through his love for work, his wonderful achievements and other noble traits, the Airedale has reached his present popularity. It is character that has made him the most popular at most of the present day shows, and not the prizes that he has won.

\section{The Show Type}

This is the class that represents large investments, brings long prices and great pleasure when you succeed in getting a "to.,per." Notwithstanding we frequently have persons say they have a perfect Airedale, as a matter of fact the perfect one has not yet been bred and may never be produced. The person who is able to furnish one very close to the standard has a snug little fortune in sight. One that so closely approaches the standard as to be able to defeat all others, and that has good strong blood lines, is worth well into the thousands.

There are two ways of owning these. The shorter way is to buy them, if one's purse is of sufficient length. This does not mean that you will be able to reproduce what you have bought. There are many persons in the business who gain a great deal of distinction and no little pleasure in this way.

There are others who do not know what to do with them after they have gotten hold of them and the dogs soon begin to "go down hill" and the owner becomes discouraged and some shrewd doggy fellow comes along and gets a bargain.

The longer route to obtain a "topper" is to breed it. This takes time, knowledge, thought, judgement, often the ability to withstand disappointment, and perseverence. Sometimes it takes more of all these.

What is your reward? First comes the pleasure from an intimate association with its ancestors, together with the enjoyment of their fidelity and affection. A great deal of recreation is had from handling and working them and very much more, if you are a sportsman. Then comes the mating, that you have given so much thought, th care of the matron for the next two months. Then one morning you hear some crying in the kennel and you go 
out and look the youngster over and probably decide that they look good. Then comes the pleasure of growing them properly and lastly learn what you have. If your judgement has been good and proper care and attention has been given you are sure to have something of value, though you may not always get "flyers." When a real "flyer" does come your way, you have gained distinction and reputation that come in no other way. Certainly the pleasure is very great or you would not have undertaken the task. It appears to be the general rule, of those who aim to breed this type, to study the blood lines that "nick" and mate so as to correct faults in the individuals to be mated, disregarding utility features. Others send their bitches to the dog that has done a lot of winning and is before the public at the time. This is all folly. Another chapter will deal more carefully on this subject.

The Show and Ltility Type

The Airedale is a worker, that is what he was made for. $\mathrm{He}$ should have brains, that is what has made him. If he is bred purely for show points and is kept in a kennel and used only for show purposes, without regard to his other qualities, can he retain the reputation he now possesses? He should have quality-and then more quality - but the writer is most firmly of the opinion that the true Airedale should possess quality and utility properties to the highest degree.

When one undertakes to breed the all 'round good Airedale, he finds it a job of more than a day or week. That is, unless he is fortunate in securing his breeders from one who made a seccess along these lines, and who is entirely honest with his clientile. By all 'round good one, we mean one perfect in disposition, in gameness, intelligence, in Terrier Quality and better in show points than most of them. Eliminate the first four qualities and the task would be much easier, but in our opinion they would not be Airedales.

True you may not be able to reap honor in the show ring as quickly, but when you breed along these lines, you are producing something there is and will always be a demand for. And if you do not always get a flyer or two from each litter, you will get something that will give you pleasure and entertainment, by his wonderful accomp ishments, and when a topper is produced along these lines, one has succeeded much beyond he who has bred for show 
points only. The demand is constantly increasing for Airedales with working ability and one need not lose money $i$, his efforts to produce the worker with quality, even though he does not have the occasional high priced showman for sale. Other chapters will deal fully with this subject.

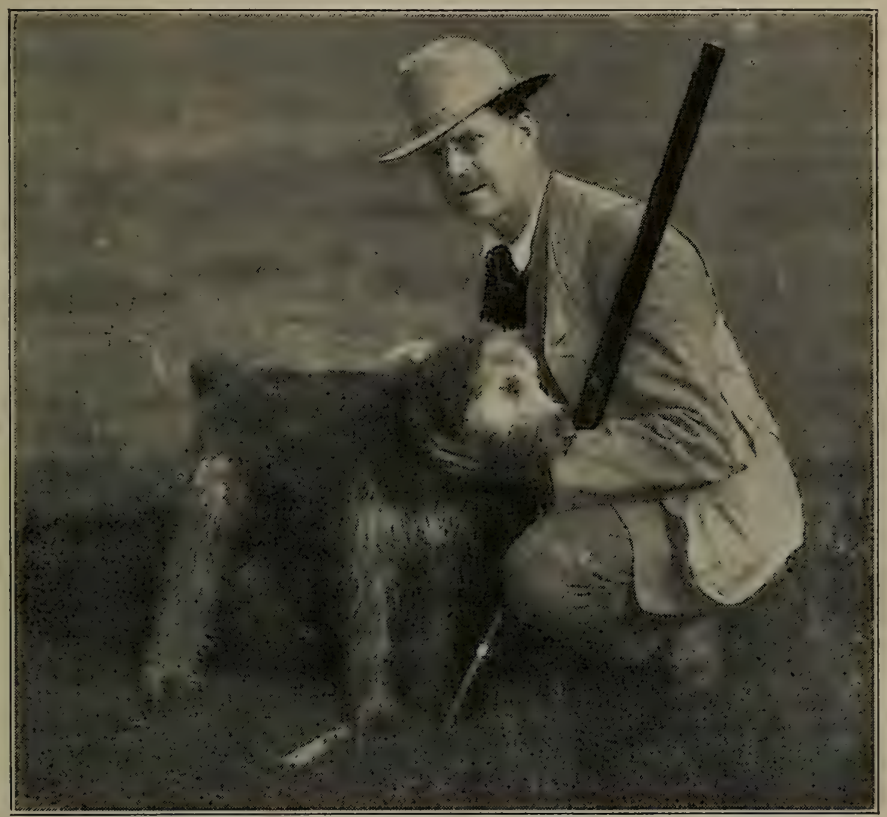

A Haphazard

\section{The Haphazard Type}

Airedales of this type just-happened-so. They are produced in several ways, Some fellow wants to own "an Airedale." He finds some other fellow who has a bitch that should have been consigned to the bucket at birth, and who informs him that he has a very fine young bitch that he will sell him for five or tendollars and immediately the first mentioned fellow is the proud possessor of "an Airedale." When time comes for mating her he goes around 
and finds some dog that he can breed to for nothing, neither owner knowing anything about a proper mating, and in a short time there is "a fine (?) litter of Airedales for sale." Some go even farther than this. We know of an instance where a breeder with a reputation wanted some new blood in his kennels. He purchased a well bred bitch, had her mated to a dog of proper blood lines and shipped to him. He was not pleased with the bitch, she did not come up to his standard, yet he hunted her and used every means to have the puppies what he would like. They were unsatisfactory and the bredeer sold the best of them for workers and without pedigree and at very reasonable prices. In due time two bitches were bred to one of the dog puppies. Both of the owners endeavoring to avoid paying stud fees. One of these bitches had a bunch of puppies that were sold as being of the strain of the breeder of reputation, the lot from the second bitch were destroyed because they were black and tan. Neither the owner of the sire or dam having sufficient knowledge of breeding to know what should be the color at birth. Others of this class are produced by some kennel owners who breed from convenience, irrespective of the important qualities of sire or dam.

In writing on this subject we are not trying to cast any reflections on any person or persons, simply endeavoring to tell facts as we see them, others are fully as entitled to their respective views. However in writing a book, if the author has no views and ideas to express, what is the value of the book? 


\section{CHAPTER III. \\ BUYING}

The first consideration for any buyer is what he wants. That is, he should have an object-a purpose - and not buy for the mere purpose of being the owner of an "Airedale."

It is usually more satisfactory to both buyer and seller for the buyer to personally select the dog, however this is not always convenient. Even the beginner can make the selection that su ts him, by visiting the kennel of a reliable breeder, and will also learn something by the call. If he is not advised he should take into his confidence a friend and get his aid in making a selection of either the dog or the breeder from whom to buy. In doing this, it should be borne in mind that not infrequently his friend may have

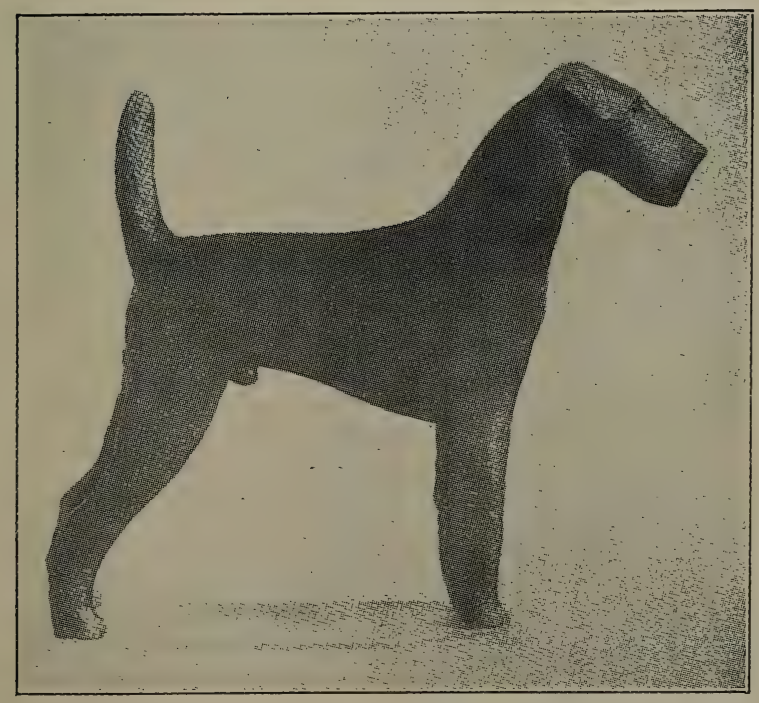

Model of an Airedale intended to represent an ideai show specimen that many are now trying for 
an axe to grind himself, in the way of a commission, or similar interest. This also holds good in having parties look the new purchase over. Buying at a show is not to be advised. It should also be in mind that even an experienced breeder may be mistaken in dogs with which he is not familiar and would only discover faults or some good qualities after a more familiar acquaintance.

We clip the following from a recent issue of the Field and Fancy. "It is not safe to buy "bargains" in dogs or to assume that the breeder does not know the worth of his stock-mostly, he over rather than under rates it. The more remarkable the apparent bargain the more dubious it becomes, for perfection is not compatible with cheapness; and "cheap" dogs-very often have nothing but their cheapness to recommend them. The dog which, though of markedly superior appearance, is offered at a very low price probably fails in breeding value, or has some serious constitutional defect that time alone will show. Really good and well bred dogs are always scarce; and to get a good dog one must ordinarily pay a good price-the better the dog the higher the price, as a general rule: Purchasers should not expect too much; and, if desirous of getting the best stock, must not, when dealing with a reputable breeder, try to beat him down too much in price. Nor is it reasonable to ask such a person to send valuable young puppies on approval, as, if refused, the double railway journey may upset them seriously. If you can not trust his word, it is wiser not to do business with him at all. Better pay a little more and buy guaranteed stock from an experienced breeder with a character to lose."

Sometimes a reputable breeder may have reason for offering something for less than the usual value he places on them. Also a breeder who is familiar with a number of the ancestors, can have a better idea of what a puppy will probably become, than can any other person. So, after all it narrows down to the reputable breeder and his knowledge of his stock.

If you wished to buy a cow, you would decide between the varieties that are noted for the purpose for which the cow is wanted. If a trotter is wanted you would not buy a colt that was bred from saddlers. One cow may give a carload of milk during the year, and be worth many thousands of dollars. Another of the same variety may be bought for fifty dollras - and not be a bargain at that. The same is true in Airedales. 
Another point to be taken in consideration in making a purchase, is the assistance and knowledge that the seller may be able and willing to give you. A desirable breeder will usually go to the trouble of writing the purchaser-especially if he is a beginnermany little things about the dog purchased, and the breed in general, that in itself, will be worth as much as the price paid for the dog.

We would advise only the experienced to try to import and cnly then from those known to be reliable.

Do not be discouraged if your first purchase does not come up to your requirements, try again.

The Airedale has the reputation of recognizing only one owner at a time, for this reason it is best that the new owner should remove the new arrival from the shipping crate and be the first new acquanintance. If he is made of the right stuff he is looking for a master and pal, as soon as he is taken out of the crate.

A puppy should first be given a little water-not too much cold water, to chill him, then a little soup or light food. After a little exercise, more food.

The removing from crate should be done as quietly as possible. First, speak to him in a friendly, quiet way, calling his name; then caress him a little and gradually get on good terms with him. He should be taken from the crate, in an enclosure of some kind, where he will not be able to escape. It might be that he has been badly mistreated on his journey and is still frightened from this, and will try to escape. Let him attend to the call of nature first, get a little exercise and probably he will come to you without being called. If he is frightened go easy with him until he comes to himself. Give him a warm, comfortable place to sleep and a few days to get over the effects of being caged up. It is not advisable to wash a dog, especially a puppy, on arrival, if his coat is foul, dust fullers earth into it thoroughly and brush it out. If his feet are tender, the bottoms may be bathed and a little Condy's fluid, vaseline or something similar applied. Don't rush him out to show to your friends, you will have plenty of time for this after he has gotten over the trip.

If the dog, on arrival, is not what you want, receive him and promptly advise the shipper. Do not leave him crated up and with the transportation company. This is a great injury to the dog, is inhumane and nothing can be gained by it. 
We might add, that it is customary for the purchaser to remit the amount in bank exchange, or equivalent with his order. The breeder must go to the trouble and expense of shipping and usually stands the risk of having the dog arrive in good condition. He should not be asked to ship C. O.D. and probably will not do so. Nor should he be asked to ship on a personal check, unless the buyer is well known to the seller. If the sum involved is a large one, the buyer can possibly arrange to have the amount deposited in a bank, to be paid to the seller, upon arrival and acceptance of the dog. If dog is not accepted, the money to be returned to the buyer, less expressage both ways.

Or, if the buyer is at all afraid to risk this sum with the seller, and is fully convinced that the seller will send the dog as represented, then he can ask the seller to give him the privilege of writing the seller's banker, or other reference.

Usually neither of these ways are necessary. The best way is to select your breeder, tell what you want and what purpose you wish the dog for, agree on the price, send the order and enclose a draft. Should any difference arise, it can then be taken up with the seller.

In all cases, unless there is a special agreement, the dog becomes the property of the buyer when he is delivered to the transportation company, the latter is acting as common carrier for the buyer, and is responsible to him for safe delivery.

This chapter would not be complete without mention of what sex to buy in the event that the person wishes only one dog. If the writer was going to reduce his kennel to one dog, that would be a bitch. We have heard the most prominent dog men in the world express themselves in similar language. The failure of the average owner of a bitch of any kind, to take the proper care of her, when in usage, is mostly the cause of so many persons wanting only dogs. A bitch will do any kind of work that a dog will. She is more easily taught, has less things to divert her attention, is much nicer to take out on the street or elsewhere and twentyfive dollars will generally buy more quality in a bitch puppy, than in a dog puppy. Our chapter on the brood bitch tells how to handle and care for them. Some breeders, the writer among them, will not sell their best bitch puppies, that are bred to suit them, till they have one or more litters from them; or they have proven to be not what they expected. 


\section{CHAPTER IV.}

\section{FEEDING}

Airedales with whom the writer has been familiar are light eaters. Where only one or two are to be fed it is an easy task, if one has table scraps. They will do nicely on these, fed two or three times a day. Sugar in any form should be avoided. It upsets the digestion and some consider it poison to any dog. No dog can digest chicken bones and we have known death to result from feeding them in quantities. Some authorities advise feeding potatoes and others say avoid them.

Where a dog is graudally taught to eat most anything, he can do so and apparently thrive on all kinds of food. This can not be done by an abrupt change.

We do not believe in making a toy out of an Airedale and trying to be too careful in feeding. Don't treat him like he was a little better than a human being, (though he is much better than many of them,) but like a real good dog, and see that he keeps a dog's place.

As the subject of feeding puppies is fully covered in another chapter, we will here assume that the dog to be fed is six months or so of age.

While the feeding of one or two dogs is of little moment, the feeding of a kennel becomes quite an item and must be figured closely or a decided drain will take place.

From the point of economy, health, condition and convenience, we have found the following most satisfactory.

Let the dogs have some exercise late in the afternoon, the more the better, and feed as late as convenient in the evening, their principal meal.

We secure meat scraps from the butchers, bones included, place them in the cooking vessel, add sufficient salt and a little red pepper and occasionally a piece of garlic. Over this place enough water to cover and when well cooked sufficient water is added to make the desired quantity of broth. Occasionally some vegetables are added and cooked with the meat. Also once or twice a week some raw beef is fed, after the regular meal. Different individuals must be fed differently. Make the food suit the dog and not the dog to suit the food. Each should be fed what he will consume in a 
few moments. Some times they will eat only a small quantity and finish up a few minutes later, but what is left uneaten should be removed from the kennel after 30 minutes. As an exemplary meal, take one pint of bran, one-third pint of middlings and onehalf pint of rolled oats. Place these in the feed pan and pour a sufficient quantity of the broth over them to moisten-do not make it sloppy-but so that it will crumble or stand up. Add to this such quantity of the cooked meat and bones as each individual needs.

The rolled oats used are the ordinary table oats and are bought in 90 pound sacks. They are steamed in process of manufacture and need no additional cooking. The bran and midds are also fed without any cooking.

The quantity of each used is adjusted to suit each dog, feeding what they will clean up. If the dog is thin in flesh or one that requires stronger food, the meat and rolled oats are increased. If he is a hearty eater and in good flesh, the bran is increased and other foods diminished. This will satisfy his appetite without increasing flesh. Stronger food should be given in cold weather than in warm. Some meat is desirable at all times, but less in summer.

In the morning the dogs are turned in the exercising yards while their kennels are being cleaned and are allowed to take some exercise. Sometimes they are given a run. The morning meal is a much lighter one. This one is made to vary quite a bit. Bread is sometimes cooked of bran, midds and corn meal, seásoned with salt and some grease from the fat meat scraps. The bread is sometimes fed dry, again is partly broken and broth put over it. Again we feed the ordinary dog biscuit, either dry or moistened. At times a pan of broth alone is given. Butter-milk is obtained occasionally and given alone. It is a good liver regulator. At times some will enjoy a dish of dry rolled oats, or oats with a little bran mixed. Some will eat quite a quantity of dry bran. It is a fine cleanser and will do no injury.

Frequently it is best to leave the meat out of the food and thirty minutes later feed the meat. This causes them to eat the other food.

Hot foods must be avoided, but slightly warmed in winter is an advantage in providing heat. A dog's mouth is much more easily burned than a human. 
The dogs nature has been much changed by his association with man and his food should be somewhat similar, yet, there is still quite a bit of the wild left in him and this must be catered to.

If the scraps are a bit old, or the broth has soured some, there will be no harm come from its use, provided each has been kept in receptacles that will not generate poison. We would advise against feeding soured soup to a bitch in whelp. Bones are splendid, they improve the digestion, increase the jaw power and enable kenneled dogs to while away much time. Bones should not be left either in the kennels after the dogs are through with them, nor in the exercise yard at any time. Fights will result over a bone more quickly than from most any other cause. If bread from white flour is fed in any quantity, bran should be fed with it to avoid constipation.

If a dog is in good flesh and does not eat, let him miss a meal or two. In other cases, after he has gone a day or more without eating, or it is seen that the stomach is off, it is well to give a tablet of charcoal, bismuth and pepsin, three times a day. A good substitute for these, and a very good thing to give all of them at times, is a condition powder made at home. Select a pint of wood ashes and the charcoal that is in them. Rub this through a seive, a teaspoonful of salt, two ounces of sulphur and two ounces of powdered copperas. All should be put through the seive and fully mixed. Give about a teaspoonful once or twice a day in the food. For the benefit of the coat, some give a teaspoonful of sulphur in food once each week. This is also a tonic, and when given in large quantities we have seen it remove worms after many other things have failed. No harm will come from it. If a dog is to be fattened, it is well to feed him frequently and not too much at a time. Give freely of rolled oats and meat, both cooked and raw. A dog biscuit between meals, or something that appeals to him.

They should have a sufficient quantity of fresh water and the water and feed vessels should be regularly washed and kept clean. When dogs are being worked the food should be much stronger than when they are idle.

Dogs should not be fed from the table when one is eating, it is not the proper place for them.

If dogs are fed along the lines indicated herein, there will be no trouble from worms. We have taken new dogs into our kennels, fed them in this way and have gotten them rid of worms without 
the use of any drugs. It will not always rid a dog of tapeworms, but it will make things very disagreeable for the tape and rid the dog of large portions of it. If one discovers that a dog is infested with worms, a small quantity of red pepper should be sprinkled on the food, after it is prepared in the plate and ready to feed. Pepper should not be given to young puppies.

When one is on a camp hunt, food for the dog sometimes becomes quite an item. W' 'hen a dog is hunting he can digest most anything. Rolled barley, (horse feed) whole corn and the carcases of wild animals, that they ordinarily would not eat, can be used. The meat should be cooked and seasoned. 


\section{CHAPTER V. \\ THE STUD DOG}

The conditions are so varied, as to what one might want information concerning a stud dog, one scarcely knows what to say on this subject.

If one is going to buy a stud the chapter on buying should be of value to him. If he has bitches to mate with him, the bloodlines and defects of the bitches should be taken into consideration. Of course, get a dog that should correct the defects in the bitches as far as you are able. And the blood lines for either out-crossing or line breeding as you may like. Read chapter on matings.

The number of really good stud dogs, by this we mean real sires, is very small. Mr. William Haynes figures that so far there have been some sixteen great ones. To read the kennel papers one might conclude there were multitudes of them.

Whether he is bought or the bitch is sent to him, he should be a good one. This goes without saying. He should have a strong pedigree and personally we like to see a champion bitch appear in this pedigree within three generations. There have been a number of extra good bitches that have not become champions and we have seen these crop out to the fourth and fifth generation repeatedly.

He should be a quiet, game Terrier. Should be well controlled and kept so in a way that will not ruin his disposition. Please get that, control him, but don't ruin his disposition. Give him exercise and care that will make him think he is your pal. If he gets wrong when you have bitches that are in use, make him mind, but with as little whipping as possible and keep the bitch as far away from him as convenient and out of his sight. Place her in a room on the second floor of a building, for it appears that the dog can not get scent of her very well then. Put in shipping crate, if no other place for her.

If the stud is made of the right stuff he is going to be boss of all the other dogs and his master also, if the master will permit it. Young dogs that are coming on should be kept away from him at all times. If he decides they are getting too important he will take some of it out of them sometime. This does his disposition no benefit and may seriously damage the young fellow and cause 
him to lose his courage. Puppies should also be kept from him, he may tire of their caresses and cut them very badly.

There can be no set rule, for what works in handling one dog may be a failure in another case. If a man expects to make a success in the dog game without using his brains, he had better quit the game early. It requires brains and work to produce good ones and the same ingredients to handle them. We do not believe in severely punishing a dog, if it can be avoided. In one case it may make the dog and in two other cases it may ruin him. We do not recall having soundly whipped but one stud dog, of the several we have owned. He was Champion Clonmel Rough and Ready. When we got him he was reported to have killed five dogs and after being with us for a short time he was turned into a yard where a kettle of beef scraps were cooking and a seven months old dog had assumed the task of watching them and objected to "Ready" getting too close to them. "Ready" promptly went for the youngster's throat. He was pulled off and given a little cuff. Instantly he was after him again. This time we took him by the back of the neck and gave him a severe shaking. This only made him the more determined and when the most convenient club was used on him, he turned on us. The young dog was locked in a kennel, a good chain and collar was placed on "Ready" in a very few seconds and a hitch was taken around a post. Then a sound thrashing was administered with a piece of rubber garden hose. We were the best of friends after that and while he hever had a chance at another young dog, we have seen puppies worry him on many occasions without being harmed. He possessed terrier quality that it was necessary to control. He spent several months at the San Francisco Exposition in 1915 with several of our other dogs and on the writer's last visit to him, shortly before his death, he was looking ketter than we had ever seen him, yet he was so affectionate, and seemed to beg to be taken away, or to go with us, in such a way that we will never be able to forget the incident.

This little story has never been told before and is not written in a boastful way, but as an illustration in handling and the fidelity of a good Airedale. By his acts he plainly said that he thought more of us than the many handlers he had had and wished to go home again. A noble fellow he was, peace to his ashes!

The stud dog should be kept in good strong flesh, but not fat. Should have plenty of exercise to keep him hard and at least his 
head and neck should be kept fairly well stripped. He should be regularly groomed each day and kept in a perfectly good kennel. Frequently if a bitch is placed in the kennel with him, particularly at night after he has eaten his food, it will make him more quiet.

When he is fretting over a bitch it is much more difficult to properly feed him and sometimes about the best one can do is to get him to eat a small quantity of the strongest foods.

If he is a young dog he should have some training of some kind, the more the better.

If he is to be used for show purposes, large bones should be kept from him, for he will wear his teeth off too soon.

He must be kept free from worms or bitches sent to him will miss.

As to the age at which a stud should begin his duties, there are many views. We know of some that have gotten some of their best puppies when they were ten months to a year old. Others will not use them until they are well past a year old. Many agree that he is best at two or three years of age and that he will then sire stronger puppies than when younger. However the bitch may have much to do with it, and her management while in whelp has much to do with the kind of puppies that are produced. The English have the world bested when it comes to breeding dogs and they usually do not use a dog for stud pruposes until he is pretty well made up and that is generally from eighteen months to two years. If he has been well brought along and is a good vigorous felkow, we think it well to have him serve a bitch when from ten months to one year old. It will improve him in many ways. He will have more "pep" and leave off his puppy ways. We do not think it advisable to keep it up when begun at this young age. In some cases it is well to have him serve a bitch at this age, if it is only a mongrel.

Except he be a very fine specimen, his pedigree is more valuable than the dog himself, for the pedigree will most likely do the producing and not the individual dog.

The management of the dog has very much to do with his quality and the results he attains in the stud. A dog that has beaten the best of them and then placed in the hands of one who knows not or cares not, what to do with him, lets him become affected with 
worms and otherwise out of condition, will be defeated by very ordinary dogs and fail in the stud.

Continuous showing vill sometimes impair fertility but not necessarily affect the quality of the offspring.

There is a tendency on the part of many to have the owner of the stud take a puppy or puppies for services. As to one doing this, it is purely a matter of business and for he alone to decide.

As to refusing inferior bitches, this is also a matter for the owner of the stud to decide. The class of bitches served have a most important bearing in the matter of judging the quality of the get of the dog.

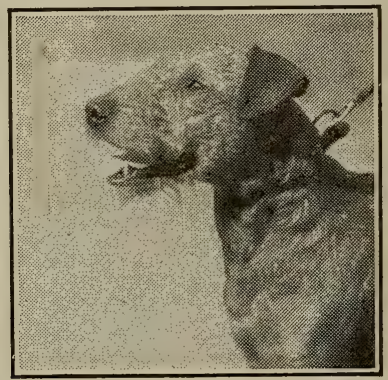

Ch. Clonmel Rough \& Ready 


\section{CHAPTER VI. \\ THE BROOD BITCH}

The selection of the brood bitch is governed by very many things. So varied are these it is impossible to say anything that would fit all instances.

The writer figures that the bitch, if she be a good one, is from sixty to ninety per cent of the mating, depending upon the individual character and pedigree of the bitch. By this we mean that a bitch of strong individuality and strong breeding, will have mu:h more to do with what is produced from the mating, than will any sire, no difference how great may be his reputation as a sire. Good bitches are absolutely necessary to the production of good ones, no matter whether they be for show, or utility purposes of any nature.

If we were to undertake to describe a perfect brood bitch, she would be of fair size, a champion or at least one that had done some winning in good company, by a dog th it had produced something of note and out of a bitch that was good, and having a pedigree full of good ones. The more good bitches the better. We would want her to be a terrier, game, true, exceedingly intelligent, a worker and companion.

Some contend that large bitches do not throw good ones. We have not found this to be true. At the present time the tendency is to produce big ones that are good, some good judges contending that it is more difficult to produce a good big one than a good small one. If they are to be made larger, then in our opinion the size must come mostly from the dam. However, if they are to retain the terrier quality, this must be largely present in the bitch. Many large bitches do not possess this, which fact no doubt, causes many to conclude that a large bitch can not throw good ones. She will not, unless she has the qualities above described. Feed and care has much to do with what the puppies will be, but it is not always possible to grow puppies from the smaller bitches, as large as some want them today. A bitch may be under size from bad rearing and yet be from large parents. In such cases she can be expected to throw at least some that will make into specimens of good size. However if many small ones are known to be in her pedigree, she can not be expected to get them up to size, 
even though she be mated with a large dog and one that has sired large ones.

A good bitch of medium size, possessing lots of "nerve force," she out of a good, large one should be an ideal to produce the kind preferred today.

As the dam is most likely to largely govern the color and coat of her puppies, no little attention should be paid to her selection as to these points.

She should be educated by hunting or other accomplishments. This will aid materially in the working qualities of her offspring and will add materially to their utility qualities.

After the selection comes the care of "madame." She should be given sufficient exercise to keep her in condition and such food as will keep her in good flesh, but not fat. If too fat she may miss when mated. She must be kept free of worms, for the same reason.

Airedale bitches usually come in use at from nine to fifteen months of age, more frequently around one year old. By many it is thought best to breed her the first time in, it developes her and bring her to maturity more quickly. If she comes in rather early, and is on the small size, one should use judgment as to breeding her. Frequently to breed the first time and let her pass the second time without breeding will grow her out better than if she were allowed to pass the first time. Breeding them when young does not seem to affect the quality of the puppies but continuous breeding of bitches that come in frequently, will injure the puppies. When a bitch is not mated at time of use she will usually come 'round again in four to eight months. If she is bred and raises a litter, she may be expected to be ready in from six to twelve months. Usually from six to eight months. We have heard of cases where they have raised three large litters in a year. It is absurd that quality ones can be thus produced. Some parties interested hold this out to prospective buyers to convince them of large profits in the breeding game. In a kennel of several bitches it is usually safe to figure on about one and one-half litters per bitch per year. From many causes some will miss occasionally and some young fractious bitch may lose her puppies by worrying and fretting the first few days after they are born. If a bitch contracts distemper at about the time she is bred, she is almost sure not to whelp.

Before the bitch is ready one will of course figure on the dor. 
she is to be mated to. This is covered in our chapter on right matings.

As a rule she will menstrate for nine to eleven days before she is ready for service, however each individual will have her own peculiarities. Some will have luchorhea for several days before menstrating. We knew of one case where the bitch menstrated only about five days and if she was not bred at once, she would go out within twenty-four hours and have nothing to do with the dog. This is very rare. Most of them are ready in ten to twelve days after first signs of menstration. To be on the safe side they should be securely kenneled after the first three days. By securely kenneled, we mean they should be placed where they can not possibly stray off, by breaking out, digging out, climbing over their enclosure or unfastening the door or gate to the enclosure. The same precautions should be taken that no dog gets to them in the same ways as just described.

Some contend that a bitch that has "caught" will go out very quickly after being mated. This we think depends very much on the peculiarity of the individual. We do think they will go out more quickly when the mating has been a success than when no mating was had or it has been a failure.

There are many ideas about breeding to control the sex, but we think very little of the most of them. If there is anything in any of them, it is that of breeding late in the period to get the more males. It may be that nature has provided in this way to evenly distribute the two sexes. That in the wild state and males were plentiful, thus causing the mating as soon as the female would accept it, thus producing more females. On the contrary, if males were scarce and the female was required to travel for days before her scent was picked up by a male, this causing the mating to take place late in her period, then males would predominate, to make up the shortage of males. Whether this is true or not, most breeders follow the rule to mate as late in the period as is considered safe. Endeavoring to mate along this line we have had both sexes to predominate. In one instance we had a litter of nine males and no female.

Litters usually consist of from six to fourteen puppies.

As to one or two services, that is a matter for the owner to decide. If the bitch has not been mated before, we think two services are better, with one day intervening. Same should be true in breed- 
ing to a dog his first service. Also the condition of the flesh of both dog and bitch should be taken into consideration. If either are fat, or are known not to be at all times "sure," then two matings should be had. If both are sure and the bitch is inclined to have large litters, the writer uses only one service.

After one is absolutely sure that it is safe to have her out, after being bred, the bitch should have her usual exercises and it is better to work her, of course keeping her in good flesh. She should be made a "pal" of as much as possible and to do as many things as are convenient, that are useful to her owner. This will aid in producing health and useful puppies with the correct dispositions.

After about four weeks she should be given the best of foods only and the last two or three weeks should be fed on the strongest of foods four to six times per day. Large quantities should be avoided at this time and no useless substances should be given. If she is going to produce a large litter and is fed in large quantities during the last few days, pressure will kill some of the puppies and even greater trouble may arise at the time of birth, from some being dead.

The day before whelping she will probably refuse all food and may occupy herself in preparing a nest.

After she begins to show in whelp, which will be in about five weeks a teaspoonful of Calcium Phosphate should be given in her food each night and morning and continued till the puppies are weaned. This is to aid to producing large bone in puppies and also in keeping her milk sweet when nursing.

If she has been properly fed on only the best and most nourishing foods her bowels will be quite lax. If otherwise, she should be given a laxitave just before due to whelp. Much better to avoid this by proper feeding.

She should be entirely free from fleas before the puppies are due and the bed such that it will remain free of them for at least some time. She can not be treated for them while she is nursing young puppies and the puppies can not be treated for them until several weeks old.

The period of gestation is from fifty-eight to sixty-five days, commonly called nine weeks. If every thing goes well the puppies can usually be expected in about sixty to sixty one days.

It is best that she be kept away from dogs that will jump on her to play or otherwise annoy her, for three weeks before whelping. 
At this time she is placed in her whelping quarters, which should be roomy and well aired, but somewhat quiet and the house so arranged that she cannot be seen by other dogs while whelping. The floor may be a temporary one of wood, to be removed a few days before time. The ground floor should not be in the least foul nor dusty, yet should not be wet, especially if weather is cool or cold. When it is seen that she is in pain she should be left entirely alone, except that fresh water should be kept near by. She will dig out a bowl shaped nest in the ground about the size of a large dish-pan and it may be four to ten hours after the first one is born till the litter is complete and during this time she should not be disturbed at all. If all does not go well, she will let it be known and if all goes well she will be too busy dressing her new family to care for any visitors around.

After the puppies are all dried off, it is well to go in and look them over and if any are dead they should be removed, otherwise let them alone till twenty-four to forty-eight hours old. At this time they may be carefully looked over and if too many and no foster mother is available, the surplus should be destroyed.

When feeding the mother before and after the puppies come, it should be borne in mind that you are not feeding one dog, but many and that one stomach must do all the digesting for the lot. This also must be kept in mind and largely govern the number that are kept with the mother. Many persons want large litters and try to raise them all. Some well known breeders who have made a success have a rigid rule of never leaving more than six with the mother. The policy of the writer for some years, has been to be governed by the appearance of the litter, their breeding and the condition and prospects of the mother as a feeder.

If the litter is largely composed of females and not from a most excellent bitch, we have reduced the litter to four. If it is the first litter of a young bitch that is on the small side and not any too promising as a milker, we would not leave more than six. If she is known to be a good mother, of good size and in splendid condition, and we feel that we will be able give her extra attention, also, if her puppies are especially desirable, we leave as many as eight.

Airedale bitches usually are the best of mothers and frequently will take puppies not their own, if at all in condition to nurse them. Sometimes a bitch that was bred about the same time as the mother 
and for some reason has missed, will gladly adopt the puppies and quickly come to her milk and fully provide for them. Nothing but a good healthy bitch of any breed should be used as a foster mother and the puppies taken from the mother should always be left with her till they have gotten some of her first milk. This is a laxative and starts their little internal machinery to working properly.

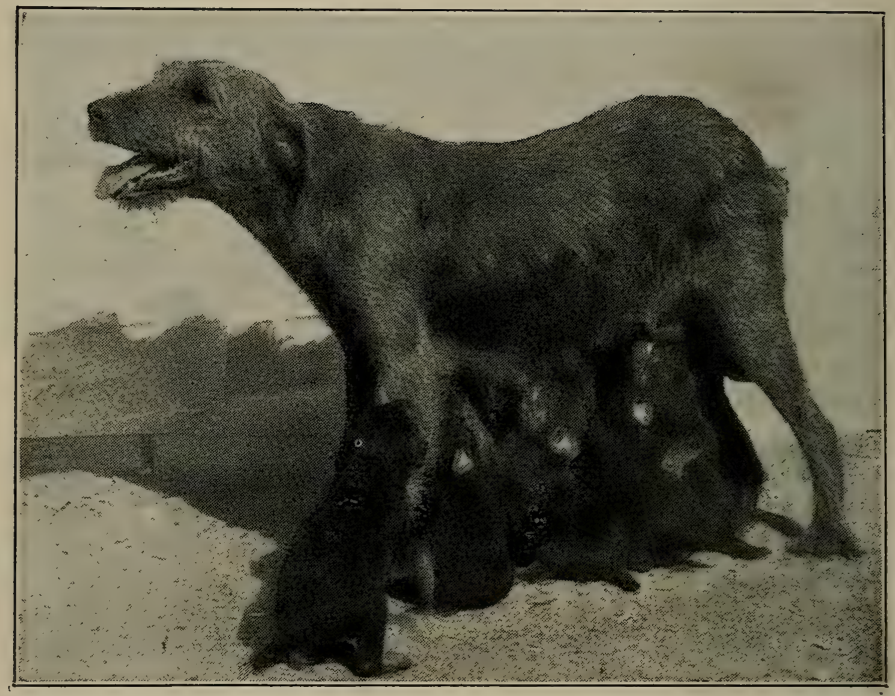

Feeding time. Litter by Ch. Midland Royal

Before the litter is born we make a frame about $2 \frac{1}{2} \times 3$ feet, from $1 \times 4$ lumber and on one side of this frame is tacked most securely a gunny sack that has been ripped open and not too tightly stretched over the frame. When several hours old, we take the puppies from their bed of nature, slightly fill up the nest and place this frame over it with the cloth down. If properly made the cloth will drop down into the nest and the four inch wall will prevent the puppies getting away from their mother. They are able to crawl over this cloth and the nest will cause them to roll back and remain near the mother, in the event they are too much 
of a rambling nature. These frames are changed daily and the hose is turned on the soiled ones and they are left in the sun till needed.

When the mother first manifests a desire for food it is given in limited quantity and very gradually increased. If any indications of indigestion are shown - and they are very likely to appear during the first few days - she is given a tablet of charcoal, bismuth and pepsin three times each day for two or three days.

As the mother 'rounds to, her food is gradually increased and she is allowed out of her kennel for a short time. Also when the puppies are several weeks old and able to follow her up, a shelf should be provided for her to get up on, to avoid the youngsters constantly annoying her. She should have a little exercise and some little attention paid her, such as a slight brushing, taking into the residence for a short time, or "any old thing" for a diversion. Having a bunch of husky youngsters always working on her gets quite monotonous and she may get tired and not want them to nurse to the age that is best for them.

Nursing bitches should be fed quite freely on raw lean meat, if ground it is much more easily digested. 


\section{CHAPTER VII \\ RIGHT MATINGS}

No difference how carefully correct may be the mating, unless the offspring therefrom be properly raised, the result will be disappointing. Also no matter how much may be written from experience, there will be many who will have their own ideas as to breeding what is desired by them; while others will be guided by conditions that surround them rather than by proper thought and desire. Still others will "trust to luck."

First we might say, that only healthy specimens should be mated. Yet once in a great while it is the making of a bitch to let her produce a litter.

One, of course, should fully decide what he wishes to produce. If he is after exhibition stock the mating should be made from stock or strains that have a reputation for having produced winning stock. It is frequently better to breed to the sire that has produced a famous show specimen than to breed to the said famous one. He may not possess the prepotency of his sire. And by the way, this same prepotency has the faculty of cropping out in most unsuspected places. One dog may possess it and yet all of his brothers from the same litter may lack it. Real sires are very few. Careful breeders consider it the height of folly to breed to a dog simply because he has won a lot of prizes. Better find out whether the proper blood-lines are back of $h \mathrm{~m}$ and see if they are such as are suited to the bitch that is to be bred. Also if each have the same fault or faults; or their immediate families have the same faults. We would rather breed to a ten dollar dog with a thousand dollar pedigree than to breed to a thousand dollar dog with a ten dollar pedigree.

Some one has well written hat to breed dogs intelligently, the breeder should know the sire and dam, the grandsire and granddam, and all their brothers and sisters. To breed intelligently one should at least know many of the dogs that figure for three or more generation in the ped grees.

Then whatever be the faults that exist in the dam, there should be an effort to correct them in the sire to be chosen. Few Airedales have the short backs that are required by the standard and bitches usually have longer backs than do the dogs, and this is generally allowed them, in judging. Yet, of course, it would be folly obreed a bitch that is long in back to a dog that has the same well defined fault in himsel, or to a dog from a family known to 
have this failing. The same is true as to light eyes, heavy ears, broad skulls, bad fronts and feet, short necks and heads, snipy muzzles, low set sterns, soft coats and many other short comings. It is plain then that any fault that is present in one of the individuals should be corrected in the other.

It should also be kept in mind that no difference how well formed otherwise may be the individual, a nice long arched neck will put a finish on him that can not be overestimated. Here comes one of the serious problems in breeding toppers according to the standard. Long heads and long necks usually accompany long backs. Also specimens that have the hard straight wire coats demanded by the standard, usually are short on whiskers (or furnishings.) The present day high class Airedales do not have the whiskers that were formerly looked for. The strong foreface is supposed to be made of bone, and a slight chin whisker (goattee) placed under a straight barrel jaw is what is now expected to give the square mouth and other head points in this section. A bell shaped muzzle is most desired and seldom seen.

Twenty five years ago, George Wilkes' sons crossed on Mambrino Patchen mares produced the most and best trotters. The same thing appears to be true in Airedales today, for the crossing of the families headed by Champion Crompton Oorang and Champion Master Royal have the reputation of having produced more good ones than the crossing of any other strains. We believe that the daughters of Champion Midland Royal have produced more champions than have bitches by any other sire. Personally, the writer believes that more even litters and a more fixed type may be had by breeding from sons or grandsons of any famous dog, that have been brought down through good individuals with good bloodlines, than can be had by breeding to the heads of any of the famous families, except in return breeding to these heads.

It is for each person to decide whether he prefers to use line breeding or out-crossing and the subject of line-breeding is entirely too weighty for this hand book.

We believe in line-breeding with due regard to the individuals to be mated. For line-breeding will as surely intensify faults as readily as it will reproduce good qualities. In any kennel it is wise at certain times to introduce some new blood.

The novice lacking in knowledge to safely estimate lineage, 
will frequently find that the best pedigree for him is the name of the reliable breed.

Where results are wanted it is much better to pay a reasonable stud fee and secure a satisfactory mating than to breed for convenience. Honest efforts in the matings is the only way any of us will ever attain that much desired and enviable reputation as a consistant breeder of good ones-a reputation that will follow in history as the one worth while.

The wonderful prepotency - or ability to breed on-of Champion Midland Royal, was recently demonstrated in a litter that is line-bred and the fifth generation from him. They show certain family characteristics very plainly.

The advantage to be had from breeding to a famous dog, of the old line, that has proven himself to be a sire, is that they are, or should be, closely related to the famous ones that gave the breed the reputation for gameness and grand utility qualities, when the breed needed it to reach the plane that it now occupies, and such a dog should impress these qualities on his progeny to a marked degree, especially if bred to his descendants.

\section{Quality and Ltility ones}

The Airedale was builded for a worker-one always ready, and in our opinion, unless a continuance is kept along that line, he will surely lose much of his popularity that has been so well constructed on that solid foundation.

If persistent efforts were not continued with the famous strains of milch cows, would certain individuals continue to break the records and give more than 30,000 pounds in a year? Would hens continue to lay more than 250 and 300 eggs per year, if no efforts were kept up as to their utility qualities? If the top of the ladder may be reached in combining the individual qualities and utility purposes of many other kinds of live stock, may not the exhibition points and the working qualities of the greatest all'round dog be combined and perfected into something even greater than has yet been bred?

True it is more difficult to breed them so as to combine all the qualities that one may desire, but is it not worth while? If in a little over fifty years an Airedale can be produced that is judged the best in the show of several hundred dogs of all kinds, including some varieties that have been for centuries; and if during these 
years many are produced that will out do many older breeds in their own line of utility and do many things that no other breed can do, can not these two qualities be combined by systematic mating, educating and care?

Do you think that in utilities the Airedale has reached the top and can not be improved in this respect? If you do, we must say, you do not know them.

What would be the reward for the breeder who is able to bring out one that would defeat all comers in the show ring and surpass all others in other accomplishments? Would the several thousand dollars he could sell him for be all the compensation he would derive? Would not the pleasure the breeder would derive from an intimate knowledge of, and intimate association with such a constant and true companion be of greater value to him? The success would be a lingering pleasure in his memory to the end of his days and his achievement would go down in history. Has not the achievements of the canine race greatly improved in the past decade? Is not the future full of possibilities for man's best friend?

Do you know of any other varities whose future is more bright than that of the Airedale?

If these questions answer themselves, why not "get in the game" and try your hand?

The show points to be considered in mating for this class, are covered in the preceding lines of this chapter. To this must be added the mating for brains, gameness, disposition and fidelity. As to mating for these qualities, little need be said. Brains may be produced from mating intelligent specimens that have such in their ancestry, the more of this kind that appear in the pedigree the better. Also, intelligence can, of course, be improved by educating the individuals to be mated. Read our chapter on training.

The same is true as to gameness, with much stress being placed on proper management.

Dispositions and fidelity can largely be covered with the same words as the foregoing qualities, but these are wonderfully influenced by the ability and willingness of the handler during puppyhood and early maturity.

In our humble opinion, which is shared by other writers, these qualities are best combined in the western bred ones, because, 
in the West there is much more use for the Airedale in a utility way - there is much more for him to do in hunting game of every kind and in other work usages.

Two decidedly aged, nor two very young individuals should be mated. In either instance low vitality will likely result. If an old stud is to be used, splendid results may attain by using a bitch that is not aged. If aged bitch is to be used, mate her with a young dog. A number of real toppers have been produced in this way, especially by line breeding to a famous sire.

Wherever located, invalids will find great benefit and remuneration may be had from raising this class.

Those who desire pleasant occupation of their time together with recreation and sportsmanship, will find this a most enjoyable employment.

Fashion must be considered in breeding, and it changes and upsets one's plans. It must not be overlooked, for fashion usually has the price and he who is able to meet its requirements is able to get the increased financial gain to be derived therefrom.

\section{The just-happened-so kind}

We are pained to see that this class is going to largely increase in the future and in a few years will be seen many "mutts." Just as the farmer's wife believes that the Leghorns will lay more eggs than the Barred Rocks, instead of knowing that it is the particular strains that constitute the difference, will there be many to say the Airedale is the best dog for any and all purposes and will breed to any old thing without even going so far as to learn that the dogs mated are really made up solely of Airedale blood. Too bad that so noble a breed must recede in many instances in this way. We feel that nothing we might say would in any way lessen the crime nor further the day. 


\section{CHAPTER VIII.}

\section{RAISING PUPPIES}

We closed the chapter on "The Brood Bitch" with the puppies twenty four hours old. At about this time, if there are more than should be left with the mother, the extra ones are taken to the foster mother or drowned and buried, without the knowledge of the mother.

There are many ideas about what to destroy and one never knows how many good ones he may put out of the way. It is necessary to give the matter some thought and figure as best one can under the conditions.

Since there is usually more demand for males than for females, it is usually best to do away with the females, except where a male is clear.y too much off.

Some say destroy the undersize ones. Others, those with white on them, and so on.

Many of us believe that the best ones frequently have white on them at birth. There are two kinds of white. One that stays with them and one that leaves as the youngster grows. The stay white ones should be done away with, and one should know something of the family traits to be able to distinguish. The descendants of Champion Midland Royal frequently show quite a bit of white on their feet and sometimes on brisket. We have never seen this fail to leave by the tan growing out through (from beneath) the white. There are sires that show more white and of the stay kind. White is permissible on the brisket, but not elsewhere, therefore it is not necessary to consid :r this, as it usually diminishes till scarcely noticable.

In most of the families that we are familiar with, if the white does not appear above the foot, it is safe to believe that it will disappear. If it runs up the leg it indicates an ancestor that was not what he should have been and unless there are very strong reasons otherwise, this kind should not be kept. The writer has never bred any of this kind.

The rule we follow is quite simple. First decide whether we wish the mother to care for six or eight. Then we look the males over and if they appear good, they are put back in the nest and we look for the best female and put her back. In this way they are 
culled till the desired number are left. One can get a fair idea of the coats and retain the hard ones. The shade of $\tan$ can be usually obtained from the small spot over the eyes. If one selects by color, he is reasonably sure of having a good solored one, at least. The skulls, muzzles and bone should also be fully considered. In short, judge as best you can and retain the better ones. In some instances the females are more valuable than the males.

Old breeders contend that the puppies that show unusually black will, after maturity, retain the color of saddle longer than others.

The mother can handle quite a number for a few days, without any injury whatever and once in a great while one or two may die within the first three days and assist in the culling.

If the mother is doing well and gradually increasing in the quantity of food consumed, the puppies will need no more attention till four days of age. This is the time to cut the tails. Two ways are very easy. Remove all the puppies and leave the mother securely enclosed in the kennel. Have an attendant hold the puppy in one hand while the operator takes hold of the very tip of the tai and sever with sharp scissors, leaving fifty to sixty per cent of tail on the puppy. If a tail is cut too short it can never be lengthened, but if too long it can be shortened by a veterinarian, after maturity. A tail that is too short is quite injurious to appearance of the dog. One that is about level with the head of the dog at maturity is considered to be correct.

The other way to cut correctly is to have some one hold the puppy at the end of a board, placed on one end of a table, with the entire tail placed straight on the board. Place sharp blade of knife on tail and carefully get the correct proportion. The blade will easily go down through the tail to the board and leave a nice clean cut, as rapidly as the tails are cut, the puppies are returned to the mother in the nest and no further attention is necessary, as she will dress each one and in a few days they will be fully healed. Immediately after the tails are cut they will appear too short, at three to seven or more months of age they will appear too long, but when maturity is reached they will be the proper length, if the necessary proportion has been made.

At the time of cutting the tails, all dew claws, if any, should be removed. This is done by using a small pair of sharp scissors, curved ones being preferable, and carefully feeling for the joint that is very near the leg bone. Two or three weeks later the 
puppies should again be looked over, if dew claws have re-appeared, they should again be removed. If they are cut sufficiently close the first time, they will not likely appear the second time.

At this age, anything that is given the mother that affects her in any way, will quickly affect the puppies.

The mother should have a teaspoonful of Calcium Phosphate in food morning and evening, this will increase the growth of bone and prevent the milk from souring. If the feces of the puppies are too lax, boiled rice should be fed to the mother. Water, in which Pearl Barley has been soaked, if given the mother, will have the same effect.

The breasts of the mother should be closely watched, and if the puppies are not taking the milk from one or more nipples, they should be made to do so, or these should be gently milked. If this is not done, her breasts will likely "cake" and form an abscess If they do become inflamed, the mother should be removed and the affected parts bathed in a solution of vinegar. She may be put back with the puppies after the breasts are milked, bathed and dry.

In case of loss of all the puppies, the same treatment should be given the bitch.

If all goes well, and it most frequently does, the food of the dam should be gradually increased in both quantity and frequency. After puppies pass three weeks of age, they are quite a drain on the mother and it is not too frequent to feed her five or six times each day, not too large quantities, but of the most nutritious kind.

At three and one-half weeks of age the puppies may be fed their first meal. This should be a small quantity of fresh cows milk, that has been heated to the boiling point, but not allowed to boil. This will destroy the germs in the milk. Place the milk in a shallow pan and permit it to cool to the temperature of the mother's milk and gently dip the puppies noses into it. Very little encouragement will start them eating and the quantity and frequency may be gradually increased. Fore noon and afternoon will be sufficient the first day. After three or four days some of the meat broth should be added and gradually increased in proportion till the milk is done away with, in a week or ten days. At this time some well cooked, finely chopped, lean meat may be given and gradually increased. Soon thereafter raw lean meat, finely ground 
may be given occasionally, and as soon as the puppies are feeding well, some rolled oats should be added to their food and a small quantity of Calcium Phosphate placed in it morning and evening. All of these to be increased as the puppies grow and increase in appetite. The meal at night should be the heaviest and contain the most meat. After four and one-half weeks of age they may be fed as frequently as five or six times each day, the meal should be removed in fifteen minutes after it is left for them and a fresh supply given next time. The mother will usually be pleased to have any that the youngsters do not care for. Sour or foul foods and dishes should be scrupulously avoided.

As they grow, the quantity of rolled oats should be increased and puppy meal may be added, or the two may be alternated to furnish a variety in the bill of fare. At five weeks they should be quite interested in eating and the feed by this time should carry quantities of rolled oats, puppy meal and meat that the consistency is not at all sloppy. Corn bread and other scraps from the table may be now added. They should now be fed four or five times each day and this should be continued till they are several months old. Some will eat more frequently than others. Heavy feeders and any that are inclined to start fights, should be fed away from the others. In fact after they attain any size it is really best to feed only a few together.

Any that are not doing well should have a liberal supply of raw or cooked lean meat just before retiring at night.

Calves heads, sheep heads and bellies are very fine for growing puppies. Sheep bellies may be fed cooked or raw. Avoid pepper, yet a little may be used at the time of worming.

If some are entirely too scrappy and you wish to take it out of him, this may be done by kenneling and feeding with an older $\mathrm{dog}$, care should be taken that the puppy gets the necessary quan'ity and quality of food. To have good ones, it is necessary that they keep growing all the time.

We know of no rule as to what they should weigh at certain ages; nor how much they will take on each month. Different families and different individuals vary very greatly. Some will attain to almost their matured weight, by the time they are seven or eight months old, while others will mature much more slowly and will be puppies at twelve months. Usually the slow maturing ones are the better. 


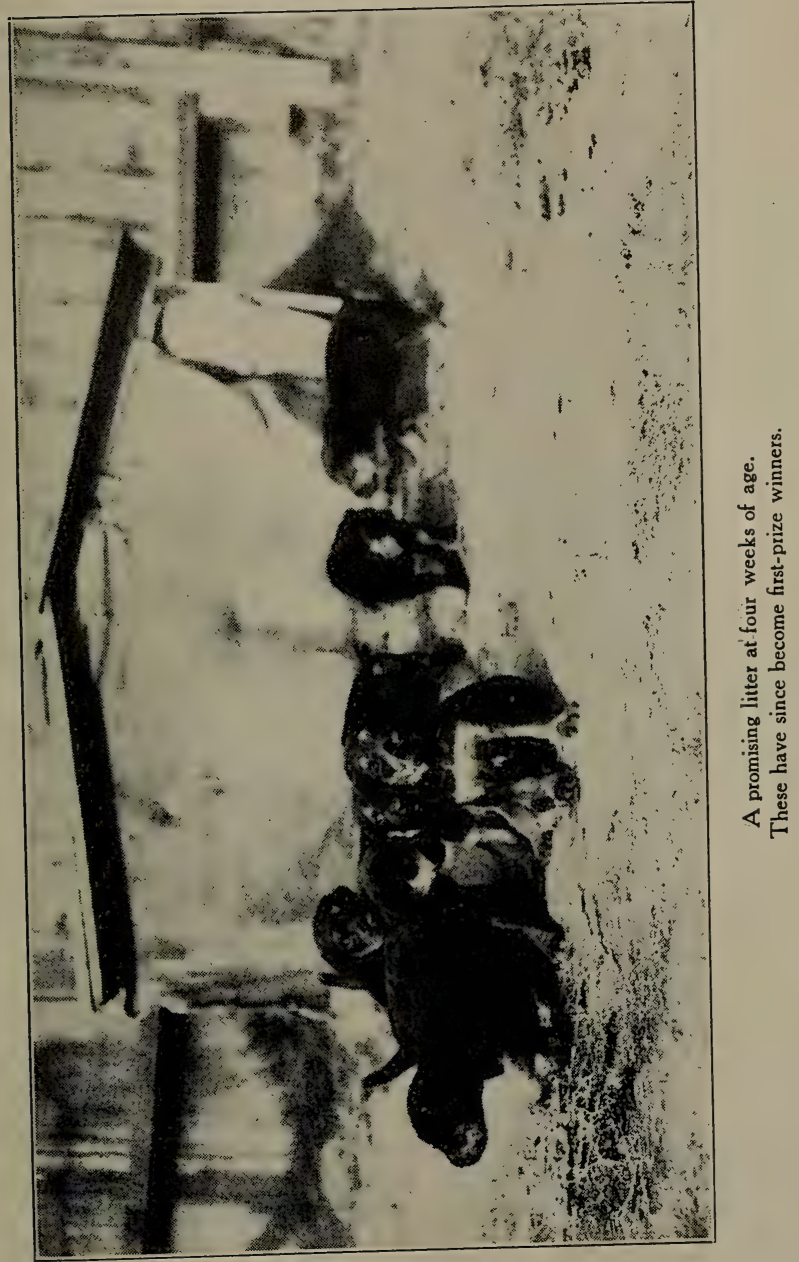


In the event of the loss of the mother and one feels it would be well to try to raise the puppies by hand, it is usually best to have a reliable woman care for them. She will beat a man every day in the week.

A bitches milk has about eight times the strength of cows milk therefore if cows milk is used in sufficient quantities to give the puppy the required nourishment, it may be seen that the quantity taken would distend the stomach and cause the puppy to be illshaped. Cows milk may be slowly heated and evaporated; orphan puppy food may be used, but really the best way, is to get them on the broth and meat as soon as possible.

When puppies are four weeks of age, one should read our chapter on training.

Better puppies may be had by feeding frequently in small quantities than by feeding less frequently and in larger quantities.

They will get their second teeth at about four months of age. Should they be overshot at this age, it indicates that they will have good length of foreface at maturity, and the teeth will most likely be level when dog-hood arrives. If however, the teeth are level at this age, it is very likely they will be undershot when matured; or will have a short foreface. Should they be undershot at four or five months of age, or before that age, we would advise their destruction, at least as far as breeders.

All puppies have worms, some have more than others. At five to six weeks of age it is safe to treat the first time. The first thing in the morning give a capsule of eight grains of freshly ground Areca Nut. Follow this in thirty minutes, with a teaspoonful of Caster Oil. A half hour to one hour later some warm milk should be given, and repeated for a meal or two, then feed as usual.

Treatment for worms should be repeated in a fortnight and continued for some months. After the second treatment the period between the dosing may be lengthened a few days each time till the last treatments are three to four weeks apart. As the puppies increase in size, the quantity of Areca Nut should also be increased. However, ten to fifteen grains should be sufficient in most cases. Some say that one to two grains of it should be given for each pound of weight of dog, yet our experience has been that no benefit is derived from giving such large doses.

It is best that food for puppies should be heated sufficiently to take the chill off. In cold weather it is too much to expect the 
little fellows to heat it in their stomachs. Yet it is very easy to burn a dog's mouth.

If milk is boiled it will cause constipation, and this should be avoided.

Constipation at any time may cause other troubles and is a material aid to worms of all kinds. One of the great advantages of feeding broth, is that the grease aids in dispelling the worms. Unless puppies are kept reasonably free from worms, they will not thrive.

If they are fed as herein described and it is noticed that worms are being dispelled, this does not mean that they should necessarily be treated for worms, but rather that the proper care is freeing them without the use of medicines.

If a shelf is arranged so that the mother may get away from the ambitious, annoying youngsters, and she be given some exercise as a diversion, she will usually continue to let them nurse till about two months of age and the weaning will be done so gradually that neither mother nor puppies will know that it has taken place. If this does not take place in this way and she is inclined to wean them abruptly and sooner than is desired, very little can be done except in increased care and feeding on the part of the kennelman.

Most Airedale bitches make the very best mothers and even after the puppies are weaned, will take pleasure in being with and teaching them to play and fight. This is very good indeed unless she takes too much pleasure in seeing a first class scrap. If this is persisted in, their dispositions may be injured so that they will be always ready for a mix-up. It is proper that they should know how to fight, and if it is bred in them, they will know how by the time they are matured. They are the roughest of players and frequently make quite a bit of noise when playing, causing some persons to think they are fighting. However, when they are made of the proper stuff and after two months of age, even the uniniated will not need to be told when a fight is started. When a fight is started it should be stopped as soon as possible, otherwise some one is going to get not only cut considerably but may have so much of the "pep" taken out of him that he will be a very long time getting over it. We want them to know how to fight and to have the "grit" to do it, but don't want it wasted on each other. 
It is not always the puppy that is ready to start a fight, that is the gamest of the lot. In some litters there will be a quiet fellow, one that is always self contained, one that will quit eating rather than have a fight, yet when the proper time arrives, this fellow may whip several of the others and then laugh about it. These quiet ones do not always show the brains they carry and frequently astonish their owner when real work is wanted. 


\section{CHAPTER IX.}

\section{TRAINING}

The Airedale is so adaptable that he will almost train himself He should be always ready and willing, and frequently have to be restrained, the more timid ones may need some encouragement at first, yet they may be the gamer when matured.

We do not like to mention punishment, for so many persons are prone to punish a dog, when, in reality the dog is wiser than they and the person needs the punishment and not the dog.

The only thing we know of that is worse than too much punishment, is letting an Airedale or any other dog be the boss and go unrestrained at all times. They are a nuisance and the person who owns such is wholly unfit to have an Airedale.

One thing should be kept in mind, that a horse, dog or most any other animal will be your master unless you show him that you are the boss. This does not mean to take a club and go after him the first time he does something he should not, but that he should be gently, but firmly, "informed of his rights." A sharp word, a pinch of the ear will inform him. A shaking by getting hold of the skin above the neck and shoulders is usually as effective as is needed. All this may be summed up in the following words. Be boss of the dog; don't punish him unnecessarily nor when he does not know what he is being punished for. Do not punish any more than is necessary. Never call a dog to you to be punished, but go to him and after you have administered the required punishment, call him to you and caress him to show that you are still his friend and will continue to be when he acts properly.

We could more than write this chapter on what others have taught their Airedales and the wonderful things they have done by their own initiatve, but you are not interested especially in what the other fellow's dog has done, but primarily in what yours will accomplish. If you have the right kind of an individual, his ability is limited only by your ability as a teacher. Whatever may be your business; whatever may interest you and be a sport and recreation for you, in these will he take an interest and be ready and more than willing to aid you and to add to your enjoyment. 


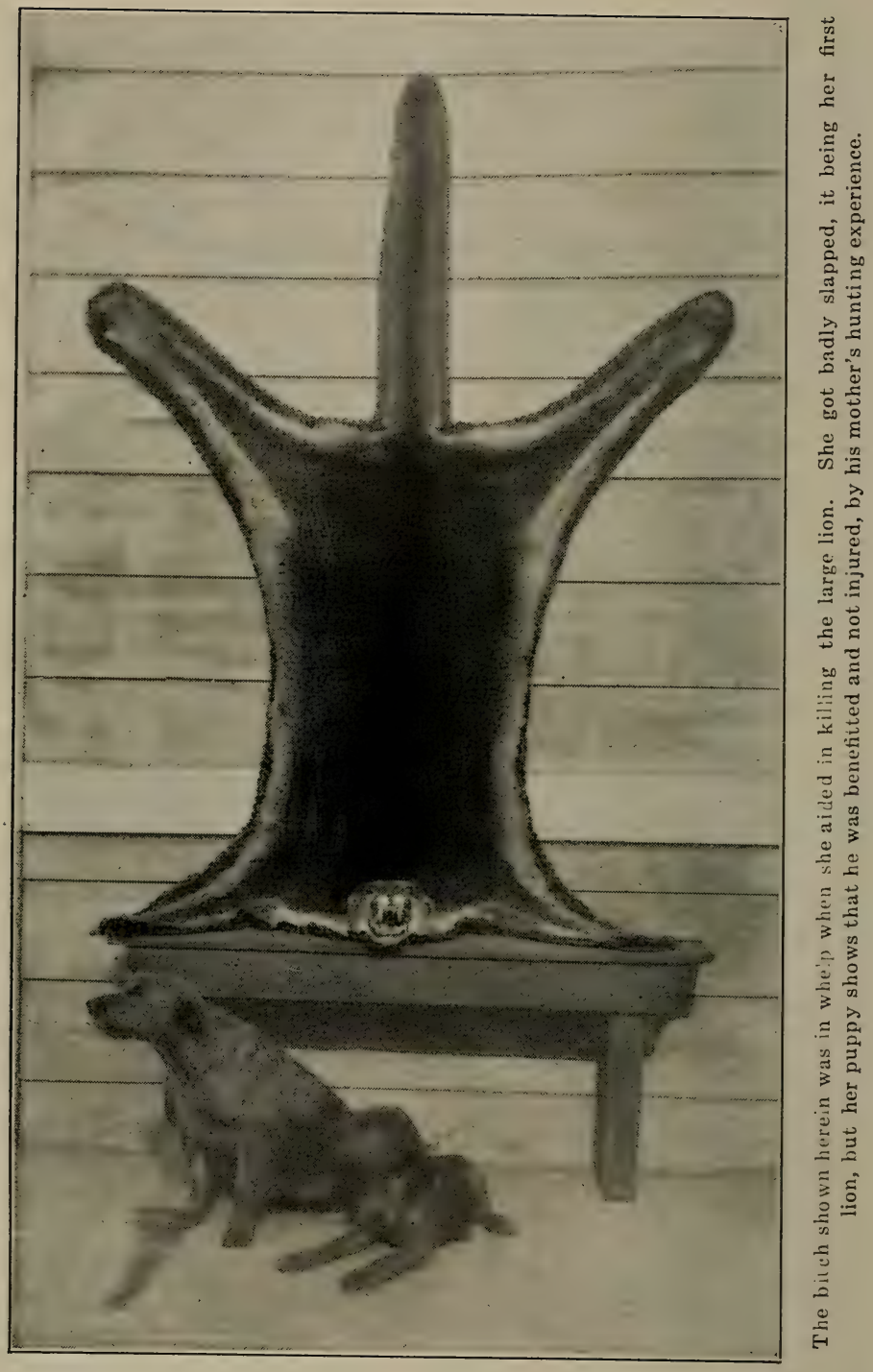


They are great students of human nature and can tell at a glance when the master is not in his usual pleasant mood.

Puppies should have some attention beginning at three weeks of age. They will quickly learn "his master's voice" and will come when they hear it in their kennel. A.t four weeks they will be ready for a little play and at six weeks we have had them to retrieve intelligently and at ten weeks to retrieve game.

At five weeks they should be allowed to follow out to where they may see strangers, vehicles and other new sights. It is much easier and much better to accustom them to strange sights at an early age. Care should be taken that they do not get badly frightened and are not run over. One can not depend on them following reliably, at this age.

After little experience in this way they should be taken out on the lead. After the collar and lead has been placed on the youngster he should have a little caress to let him know that everything is all right, and then should be asked to follow. He may and he may not. Some will refuse by sitting down and defying one to pull them. Others will buck like a bronco. In either case the only way is to go on as if nothing was wrong, occasionally calling him to come on. At intervals it is well to stop and let him get a good breath and a nice request to come further, that so far he has done well. In a very short while he will be leading nicely. Don't give him too much the first time. One hundred yards on the street and return, is quite sufficient the first few lessons, no difference whether he leads or not. He will improve each time. This is a splendid time to get them used to children. After a lesson or two a reliable child will get better results than an older person. Airedales take naturally to children and should be allowed to get acquainted with them when very young.

Should you be so unfortunate as to own one a few months old that most positively refuses to quit being stubborn on the lead, it is well to attach a chain to his collar and fasten the other end to a clothes line and leave him alone for thirty minutes or longer. The clothes line has more patience than you and is decidedly more stubborn than the puppy.

After he has well learned the lead and to come when called he may be taken out loose, where there is no danger from rigs or cars, and taught to "back" or to "come behind", these expressions being alternated with "hie on", "go on" or any phrase you may 
like. Always use the same words to convey the same meaning, at least till he gets into high school and gets more familiar with your vocabulary, then you may talk as you like. Always talk to the dog in an ordinary voice, the same as to a person. The only whistle that is necessary, is when he is quite a distance from you and you wish him to return.

After he is several months old, he may be taken out with the lead in your pocket, a cane or umbrella being used to keep him alongside. This bearing on the off-side of his collar will soon teach him to stay by your side. When this is well understood by him, you have a well broken dog for the street.

When taken for his first ride, he should have little in his stomach, as he is quite likely to become "sea-sick" and soil something. He will enjoy riding in any kind of a vehicle and will readily learn to ride on most any part of an auto. It will be very easy to teach him to remain in the machine and to watch it. If he has not had sufficient training to stay when told, he may be chained in it at first, care being taken that he is so fastened that he can not jump out and hang himself. Should he happen to be too friendly with all comers, have some one come to the machine during your absence and after fondling him, to strike him sharply on the nose with a small switch. A very little of this will make him a strictly one man-dog.

If you have no safe kennel for him and he is prone to run away from home, offer a standing reward to any one who will give him a first class thrashing, every time he is found away from home. It will do no good-but an injury-for the owner to whip him for leaving home. Let the other fellow do the whipping and the owner treat him nicely at home. Not many Airedales are given to leaving home, except to go hunting, but when one does get to be a confirmed loafer, he is the very worst yet.

\section{Teaching to Retrieve}

This is usually quite easy. First teach the youngster to come to you when called and then throw a light glove or roll a small ball, two or three feet from you and let him get it, don't hurry him, but give him all the time he needs and as soon as he has taken hold of it, command him to "come." It is best that his first lessons be given in rather narrow quarters, so that he can not run by you, nor very far away from you. When beginning with a 
puppy on any new accomplishment, retrieving or what not, always have him entirely alone, and with nothing whatever to distract his attention. If he picks the article up and only brings it a short distance, encourage him and thank him for it. He will improve very fast. Do not work him very long on any thing, he may tire quickly and when once he refuses to "fetch" and "gets away with it" it may be quite a job to make him work well. If he refuses to work, take the article in your hand, try to interest him in it by touching his nose with it and in other ways, then throw it again. If he does not then work, it is well to let him alone till he feels more like working. Frequently to let another dog retrieve in his presence, will start a youngster immediately.

After he has learned to retrieve and has sufficient age to know what is expected of him and refuses, then go to him, place the object in his mouth and hold jaws together by taking the muzzle in your hand, allowing the fingers to clasp the underjaw. Then command him to "fetch" and at the same time pull him a few steps forward. Take the object from him and pet him for this. Perhaps after this caress he will bring it for you. If so do not ask any more of him at this time. Don't worry him nor fight with him if he does not work willingly, but wait till he feels more like working. As soon as he is retrieving well, throw the object and clap your hands together sharply, to indicate a shot; say "dead bird" and as soon as he has it command him to "fetch." A pair of duck wings fastened over a block of wood by rubber will make a nice imitation of a bird and acquaint him with handling feathers. Use the same words in teaching him that will be used in the field. Shoot a twenty-two rifle over him at first and kill a bird, he will do the rest.

We do not think it wise to wash a puppy under six months of age nor to use him in water. After this he should be taught to retrieve from water. Most of them will take to water eagerly, if not, do not throw him in. If you can not get him to take to water any other way, wade in and lead him after you.

When they have been taught properly to "fetch" it is just as easy to have them bring something that will be of service to you. The morning paper, hoe, shovel, pans, gloves, slippers in the evening, or any old thing that will interest you.

To break a dog from rearing on you, put your foot on the toes 
of his hind feet while his front ones are on you. Two or three lessons will stop this.

It is just as easy for him to learn one language as another, and he may be taught different things in different languages. We have taught them three different languages. They may be taught to refuse to speak a certain language by asking, (in that language) if they can speak it, and at the same time throw a small quanity of water on him. He will soon learn to look at your hand when he hears the words, and seeing the cup will tuck his tail and get out of the way of the water. After he is familiar with the words a pocket knife or any bright object held in the hand will cause him to scamper away. Later he will need only the words.

If well yard-broken there is very little to teaching them to take to game of any kind, they will only need experience, and that you retain control of them. Many will point quail naturally, but if they do not stop, they may be readily taught to do so by command. Unless it is intended to make a rabbit dog out of them, it is best that they be not permitted to run them.

If they are to be used on big game they should not be permitted to run deer. This will interfere with them just as dces the running of rabbits by a bird dog.

If a dog is whipped before he is twelve months old it will in

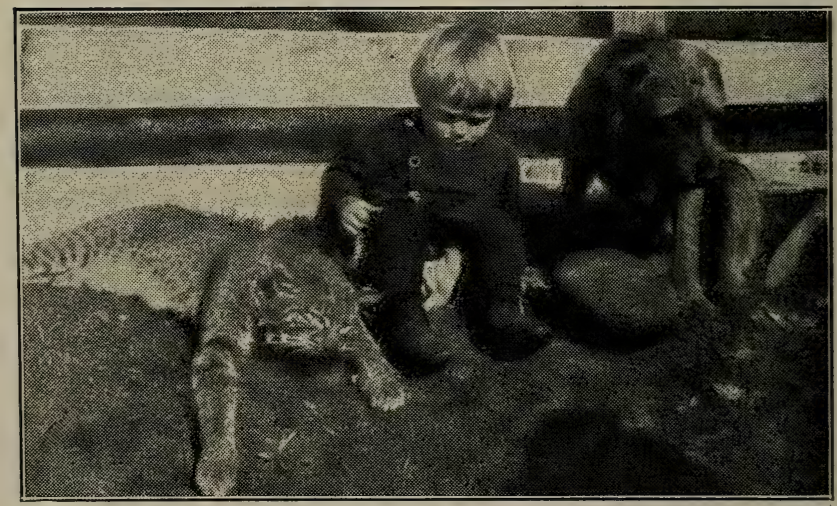

This young bitch treed the large Canadian Lvnx and then modestly posed with her "pal" for their photo 
many cases take much of his gameness away and this should be avoided.

Neither is there any reason in having a young dog tackle a coyote or other fighting animal, just to see if he can whip him. Let him learn these things gradually and save the hard tasks till there is some occasion for them.

\section{On big game}

If the bear has been treed or stopped, there is but one thing to do, that is to shoot to kill-not the dogs, but the bear. Shoot for th brain, either through the eye or other vulnerable spot.

Some fighting may be had with a lion, if it is desired. The best place to put the ball, in this case, is through his hind legs and be sure to break one or both. These are his most dangerous

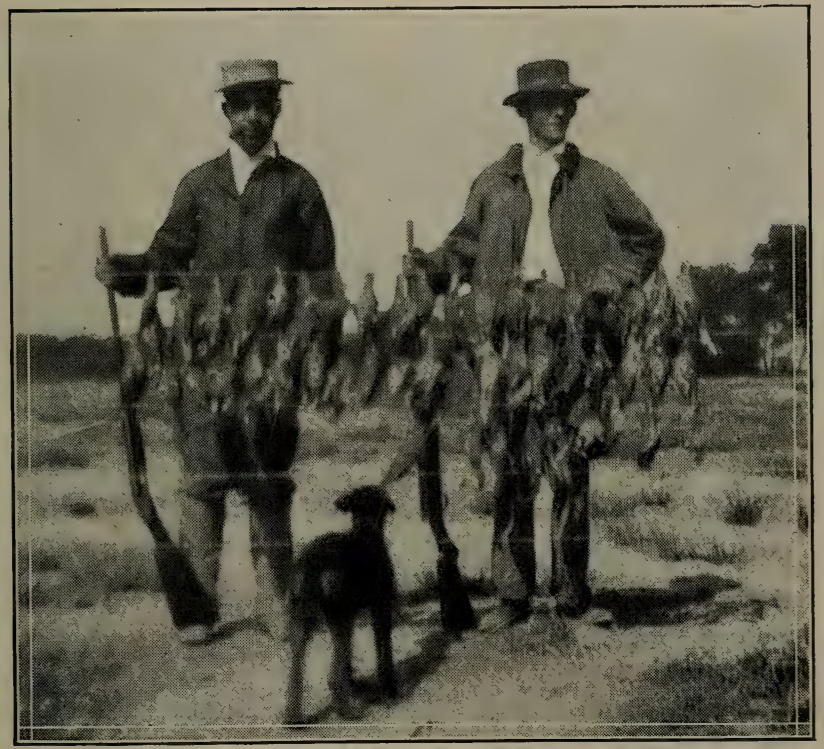

Four months old Airedale Bitch, Hy Born Lady and quail retrieved on a one day's hunt. 
weapons. We have broken the lower jaw, but this is not so safe and he may also lead you a merry chase for a distant tree, though they can only run a few hundred yards at top speed. The only gun to use on either a bear or lion, is a high power rifle, for the writer knows from experience that it is a most difficult undertaking to kill a lion with a shot gun, and we would not care to try our hand on a bear with one. To kill a lion with a rifle, shoot in the heart and hit the heart.

When young, acquaint the Airedale with poultry and other stock, particularly your angora cat. This may save much trouble later. If he kills chickens and you can not break him in any other way, tie the dead chicken around his neck and let him wear it, for some days, that is, till the French would not eat it.

Interesting him on mice, rats, gophers etc., will effectually divert his attention from killing chickens and other bad habits he may acquire.

Airedales take so much exercise by playing and are usually in fair condition for hunting, but a soft dog should not be taken out on a hot day and caused to run too far nor to hunt too hard. He may have a fit. We have had this to happen several times with spaniels, pointers and setters. Get some water on his head as soon as possible and he will quickly recover.

Stock driving, stopping chickens from fighting, remaining in the house and guarding it, taking care of children, being a companion for a sick or decrepit person and a thousand other things will come naturally to an Airedale that is endowed with brains and is properly controlled. 


\section{CHAPTER X.}

\section{KENNELING}

The Airedale appears to be able to adapt himself to a greater variaty of climates than any other breed. He is at home in hunting and sledging in Alaska and also in the warm climes.

For this reason kenneling him is largely a matter of purse and disposition of his owner. This should not be construed to mean that he should not be kept comfortable, but rather that his kennel need not be expensive.

Soils that contain much gravel or sand are very much better suited for kennels than are the heavier soils. Ground that will drain or dry quickly, is what is needed. An Airedale can stand a very great deal of cold, but like other dogs dry sleeping quarters are absolutely essential to health and working ability.

A person who does not feel restricted in the amount that he wishes to expend for kennels, will naturally have ideas of his own and will construct them to suit his plans. For this reason we feel that it is unnecessary to suggest any of this class, yet such a person may get some ideas in a general way from this chapter. Whatever may be the kind or class of house that is used, it should face the south and have window or opening on the South side that will admit the sun. It should also be so situated that the early morning sun will strike it. Cold nights are long enough without lengthening them by having the kennels so situated that the sun will not strike them till late in the day. The dog will appreciate this early morning sun more than at any other time. It is also a great purifier.

Whether closed or open fronts are to be used, drafts must be avoided. Don't put on one pound of flesh with food and shake two off in a cold kennel.

We live in a climate that varies from 20 degrees above zero in winter, to 110 above in summer, and after several years of experimenting with various kinds of houses, have deciled that the open front is best adapted for our use, except in certain instances, herein after mentioned. The house that we have finally adopted, is about 3 feet wide, some 4 feet long and nearly 5 feet high inside. The longer side is faced South and is entirely open. All other parts are made very close. The floor is detachable, as is also a 


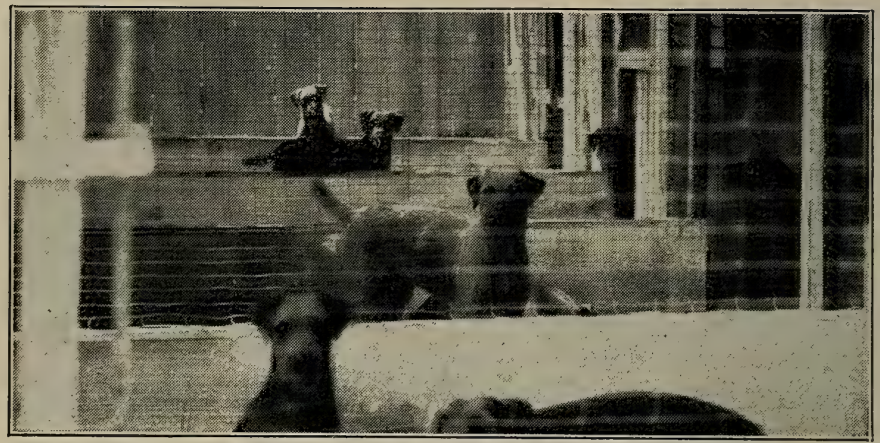

A row of five kennels. This photo does not do them justice.

second floor (or shelf) that is placed a little over two feet from the floor. Grown dogs usually prefer to sleep on the shelf. On unusually cold nights a curtain made from a gunny sack is tacked on the front at the top. protecting the upper part; or a partial board front is placed from the shelf to the floor. Either will answer and neither appear to be absolutely necessary. The yards in front of these houses are six by twelve feet and are enclosed by heavy wire fencing, except a twelve inch base above ground is of wood and eighteen inches below ground is of redwood. These fences are about seven feet high and yards are covered with poultry netting, excepting a shed roof four feet wide is placed in front and partially over the houses and so arranged that the water will be carried to the roofs of the houses and then to the outside. This arrangement makes the houses and a portion of the yards dry and admits the morning sun, but excludes the noonday sun in summer.

A dog and bitch or two individuals that will kennel well together, are placed in each apartment. Two will provide more heat in winter and will be more quiet at night, than will one dog alone. Puppies are given a little more protection in winter and several are put in one kennel.

Five or six of these kennels are made to open into a larger exercise yard, into which all or part of the dogs are liberated at least morning and evening, care being taken to avoid fights. 
The gates have springs on them and latches that are self fastening.

Such kennels are safe at all times. The Airedale is a climber, a digger and many are very clever in handling fastenings on doors and gates.

The entire kennels are enclosed by a solid fence seven feet high, with two feet of poultry netting above this, at exposed points.

Every kennel should be provided with suitable hospital quarters that can be made comfortable at all times, and where the ailing one may be kept entirely free from dampness. This may not be needed very frequently, but when the occasion arises, it is needed right now and the weather may not be the best for providing it. Concrete under the buildings and in a portion of each yard, aids in cleaning and in sanitation, as well as keeping the dogs feet in good condition. Soft dirt in yards and runs will give you loose feet.

Some digging is advisable, it keeps them occupied, teaches them how to dig and shorten their nails, thus improving the appearance of the foot. Too much of it for a youngster might have a tendency to throw the elbows out and spoil an otherwise good front.

To prevent digging at points where it should not be done, drive wooden pegs, one inch square and eight to twelve inches in length, into the ground, leaving the tops flush with the top of the ground. They should be driven in irregular rows or the dog will be able to scratch between them. Being flush with the ground they are not visible and do not interfere in any way.

In most any climate, where only a few dogs are kept, a barrel placed on its side and made steady, and supplied with straw, will provide quite a comfortable kennel. In extremely cold weather, a curtain may be placed over the end of the barrel and a slit made in it, to enable the dog to get in and out. The barrel should be in a s'ied or otherwise protected.

Where straw is used for bedding it should be frequently changed and the house swept and washed out, choosing, of course, the forenoon of a good day, to do the washing.

We use very little straw for bedding. One or two gunny sacks, one within the other, with one to three sheets of corrugated paper placed inside them, make quite a comfortable bed, is convenient, inexpensive and sanitary. When the papers become foul they 
are burned and the sacks are hung on a wire fence and the hose turned on them.

Tobacco stems may be placed between the sheets of paper to drive the fleas away.

Corrugated paper shipping cartons are obtained from the grocer and cut into sheets the proper size to fit easily into the gunnies.

In summer, if the Airedale is working, he will stand the heat nicely, but if he is idle, he must have shade. If this is not already available, it must be provided. A safely constructed tunnel is just to his liking, though there are many other ways of furnishing the shade.

In the arrangement and construction of the kennels, care should be taken to avoid as many steps on the part of the care-taker as possible. This includes convenience of water, nearness of the table on which the food is prepared, to the place where the food is stored, and in turn, their proximity to the kennel gates.

Kennel yards should be well cleaned each morning before feeding is done and the dogs turned out for a little run while the cleaning is being done. Nursing bitches and young puppies that are being fed, should have the very first attention in the morning and have their food early.

This cleaning is a very small job, if a grain scoop or large short handled shovel is provided and a suitable broom to sweep all objectionable matter; including bones, into the shovel. This will keep the coats clean, materially aid in avoiding tape-worms, greatly assist in sanitation and cause less disinfectants to be needed. When at all foul, the ground should be turned over with a spade and if long in use, the soil in the yards should be removed and new earth placed therein. Sanitation and sunshine are great requisites in a successful kennel.

No lamp should be used around the kennel, electric lights above the yards and in the buildings are best, but if not available, lanterns should be used. Even these should not be set on a board floor nor near anything that is inflamable.

Pitch-forks should not be thrown down nor left where a dog may knock them over.

A dog should not be kept in the residence during the day and then thrown into a cold kennel at night. Either keep him out of doors at all times, or house him at night fully in keeping with his occupation by day, otherwise pneumonia may result. 
Don't give him a warm bath and then throw him out of doors to dry. If he is well groomed he will not need a bath.

\section{Disinfectants}

If the kennels are well cleaned morning and evening, more frequently, if necessary and convenient; the earth spaded at intervals; sunshine admitted; houses and bedding kept clean and the dogs groomed, exercised and fed properly, there will not be much need for disinfectants, though at times they are needed.

We do not favor the lavish use of any disinfectants, no difference how much confidence one has in it. Sunshine and cleanliness will beat any that has been made or will ever be made by "mere man." A little slaked lime thrown around will act nicely.

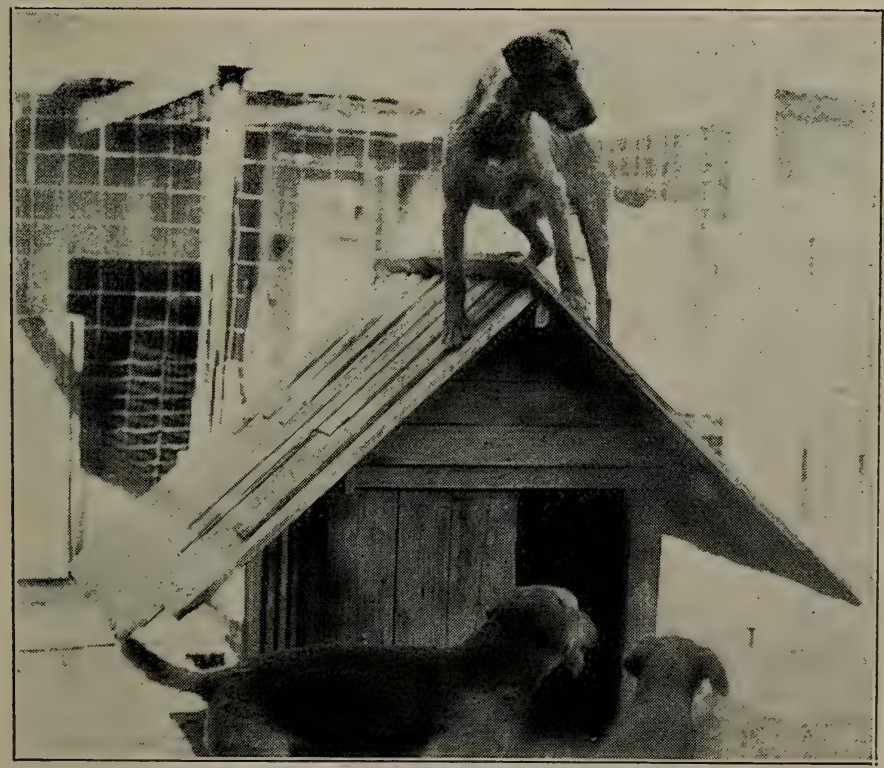

A type of house that is good for most any climate.

It is made of inch lumber and the dimensions are about three feet in every way and floor is four inches from the ground. Roof is detachable. It is especially good for invalids and weaned puppies, the lumber being tongue and grooved and put together closely; in very bad weather a curtain may be tacked over the door 
We are of the opinion that all disinfectants are not honestly advertised, by the manufacturers, and that more harm can result from their use, than can benefit. We are told by reliable veterinarians that carbolic acid in any form is a most deadly poison for dogs and we believe that some of those extensively advertised for kennel use, have crude carbolic acid for a basis. In the year 1914 we were using a well known brand of sheep-dip as a disinfectant and during the season of several months that we have no rain, it appeared to be satisfactory, but when the first shower came the dogs feet began burning them and they were nearly frantic. Later developments showed that carbolic crystal had been forming during the dry season and the rain made them into carbolic acid, (so to speak). The dogs, by licking their feet, took it into their stomachs. The result was that we had about twenty five dogs and puppies killed and injured. The older ones lived but were injured and the puppies were killed. It was extremely difficult to eradicate it from the kennels. We believe there are some good disinfectants made.

Our present kennels are located under some large Eucalyptus trees of an unknown species, and we find that they are very good as a disinfectant and deodorizer. The twigs are cut occasionally and thrown in the yards and houses and when half dry, are raked up and burned. The leaves contain quite a bit of oil and the fragrance will destroy all other odors. Dogs kenneled near these trees are also free from fleas and we recently smoked one, that had quite a case of distemper, by burning these leaves and bark, she was much improved in a few hours and soon convalesced.

We have only tried this experiment a few months, but are greatly impressed with it.

If any reader wishes to try this evergreen our kennel man has gathered a limited quantity of the seed (acorns) and will be pleased to send post paid six acorns for twenty-five cents, or one dozen for forty cents. Address, Kennelman, 2225 White Ave., Fresno, Cal. 


\section{CHAPTER XI.}

\section{DISEASES}

Like punishment, we dislike very much to mention medicines. A great many persons are prone to administer either entirely too liberally. Frequently a good "bait" of green grass will do a dog more good than much medicines. In many cases where he is in condition to take it, a good bit of exercise will also be a valuable adjunct. However there are times when medicines must be resorted to.

We firmly believe that an ounce of prevention is worth a pound of cure, when this prevention is had by keeping the dogs properly and in condition.

For all diseases and ailments there are medicines offered by well known veterinarians and manufacturers, and the remedies mentioned by us are to be usad, if preferred, or the others are not available.

Pages could be written on diseases and remedies; but our remarks will be as concise as possible, and are based on our experience only. We might add, that in the several years that we have bred and raised Airedales, we have never lost one from disease. Good nursing should be the rule and feature treating in any disease, and not dosing with medicine.

The giving of medicine to a sick dog, should be gone about as quietly as possible and the dog worried as little as possible. A nice little caress and other evidence of interest in the invalid; may do fully as much toward this recovery, as will the medicine.

Liquids are given by pulling the corner of the mouth out from the teeth, thus forming a pocket, into which the liqu $\mathrm{d}$ is poured. If the head is held up, the liquid will drain through the teeth and into the throat. Solids are placed well back on the tongue with the thumb and finger and then pushed into the throat with the index finger. Notice the dog for a few moments and see that he does not hold it a short time and then expel it. Certain medicines of either kind may be given in the food, provided the appetite is not off and the medicine such that will not be eaten in food. . Many things may be most easily given by placing them within a piece of lean beef or liver. 


\section{Distemper}

By many, this is a most dreaded disease, yet we never try to avoid it and believe that the sooner the dog has it, the better. As a rule, a dog will have distemper but once, and if a youngster, is considered more valuable when he has been through with this disease that is most sure to visit him some time. The germ is in the form of a microb : and may be conveyed in many ways.

\section{Symptoms}

This disease is so common and so familiar to all who have dogs, that it seems almost unnecessary to say much about the symptoms, though the disease does appear in different forms and in varied degrees of severity.

The most frequent symtoms are, first the dog will become languid; may or may not eat; will be cold and hunt warm places in the sun, elsewhere; then will become hot and drink quantities of water. A little later discharges will come from the nose and eyes, especially in the morning when just out of bed. Coat will appear dead and he will have no appetite. Become nervous and excitable, and when the case is decidedly developed, he may become quite "cranky" and display a very different disposition from his natural one. A dog may have a cold and discharge from nose and eyes, but this does not mean distemper. A cold will not inconvenience him very much and aside from sniffling a little it will soon disappear, if he is well fed and housed.

When his nose is cold and moist, the dog is not very sick, but if the nose is dry and warm, the ears and lower limbs either hot or cold he is liable to be quite sick. These symptoms are usually found in distemper.

\section{Treatment}

There may be preventatives, but the only way to cure a case of distemper, is to cure it before the dog gets it. That is to have him in such condition that the disease can not seriously affect him It will surely run its course, whether that be a long one or a short one.

Nursing is what the patient needs, together with the conserving of his strength and vitality. Distemper, of itself, will not kill but many complications that frequently arise, may do so. When 
we see a case of distemper among our dogs, he is at once given a good dose of caster oil, nearly half a tea-cupful for a grown one. $\mathrm{He}$ is then immediately put in a good warm kennel by himself and kept as quiet and fre e from excitement as possible. Plenty of clean water is supplied and sometimes a "chunk" of brimstone is placed in the water. He is offered an assortment of foods at the usual feeding time, only in small quantities, and if he does not eat, the food is removed in a few minutes. He is encouraged and petted and told that we know he is sick, but that he will soon be well again.

A charcoal, pepsin and bismuth tablet is given three times a day and if he remains cold, or the weather is against him, a blanket is sewed on his body, particularly around the chest, for pneumonia is quite likely to set in and this must be kept off. In extreme cases, it is sometimes necessary to take the patient in the residence and keep him warm all night. But when this is done, he must not be put out of doors till he is fully recovered, for a relapse is most likely to be fatal. Quinine may be given to keep up his temperature and he must be kept warm.

The charcoal, bismuth and pepsin tablets will benefit his stomach and bowels and get him in condition to eat, as soon as it can be done, in the mean time, he must draw on his strength and will power to combat the disease, therefore needs encouragement.

He will probably eat some finely chopped raw lean meat or liver, ihe first thing. This should be given in very small quantities at first. Again something from the table may first appeal to him. When he begins eating, don't crowd him and throw the stomach all off, take it easy, he has lots of time to get his flesh back. Keep up the tablets and give food frequently in small quantities.

If he becomes emaciated and very weak, it may be well to force a raw egg, or a raw egg and a little brandy, down him gently. Also give some nux vomica. In such an extreme case it is really best to call a veterinarian.

In our experience with Airedales, we seldom have to do very much after giving the castor oil, though we have had extreme cases in other breeds.

The past winter we had a bunch of puppies to have distemper when .wo and half months of age, and they ran out in the rain and were given no attention at all, except of course, were closely watched. They were kept in a kennel having a warm house, and the several 
of them together provided the necessary heat. They never got entirely off their feed and in only a few days were fully recovered. We have had to sew a blanket on at night and have the dog tear it off the next day and go on about his business as usual. If the dog has distemper in the least severity, and is permitted to take exercise as soon as he is anxious for it, and is then allowed to cool off, one might as well arrange for a second class funeral. Moral: Don't let him have any exercise till you know he is fully recovered, and then play the banker's plan on him, and add three days of grace. Very little exercise at first, will be fully as much as he needs. Increase food gradually and if he has any cranky ideas, be a little indulgent with him for a while. He may be som months before he is fully himself again.

A bitch is more likely to contract distemper during her first period, than at any other time, and if she does have distemper she will most likely not have any puppies, if bred.

\section{Pneumonia}

Is an inflamation of the lung tissues and may follow distemper; an injury to the lungs; or if a dog has been retrieving from water in cold weather; or hunted in the rain and taken into an auto or other rig and chilled by riding home, and then thrown out in the cold to sleep, if he does not develop pnuemonia he will miss a splendid opportunity. Keeping the dog in a warm residence during the day, giving him a warm bath and then putting him out in the cold to sleep has caused pneumonia.

\section{Symptoms}

Patient very cold and listless, head down, pained when chest is lifted or interfered with, in fact appearing to be sore all over and manifesting a desire to be let alone and if ones ear is placed near lungs a wheezing may be heard. Later stage, will sit on haunches with chin extended and difficult breathing, wheezing or rattling in lungs more defined.

\section{Treatment}

Here again is another case for nursing and care, rather than for drugs. No need to offer food, yet something in the way of warm soup or milk will be of advantage when he will take it. Don't 
offer the usual kennel food, for he is disgusted with that and everything else. Go to the trouble of making a small quantity of beef or chicken broth (don't let him have any chicken bones) and don't be disappointed when he does not eat it, but try again, without worrying him. Give charcoal, bismuth and pepsin tablets three times a day and an occasional quinine, ( 2 or 3 grains) to stimulate and keep him warm. Keep him as quite as possible, in a place where no drafts can reach him, yet where he will have good pure air and by all means keep him warm at all times. Sew two blankets on him, if necessary, and then cover him over with something, if you can get him to lie down. In many cases they will not lie down at all and it is a bit difficult for a person to put them down, without great pain to them. Pressure on the chest must be avoided. Get him to sleep, that will benefit him more than all the medicines you can possibly administer. Then let him have water that the chill has been taken from. He may not want to sleep without being alongside his caretaker or master, yet if he can get a good sleep or two you will see a decided improvement in him and it is worth your while to see that he does sleep.

After this treat the same as in extreme case of distemper and do not have a relapse.

\section{Chorea}

Is usually an after-effect of distemper or may be caused by worms; is a twitching of most any or all parts of the body. The only treatment that we know of, is to get your dog in condition. Improve his digestion and give wholesome and appetizing foods Free him of worms, if this is the cause. The case may be quite obstinate and recovery very slow.

\section{Worms}

In the matter of puppies having or not having worms, there is no room for argument. No difference how well and sleek they may appear. Therefore there is but one thing to do, treat them for worms as described in our chapter on "Raising Puppies".

In dogs the symptoms are, dead coat, discharge from the eyes, ravenous appetite at times and none at others.

If the dog is fed along the line given in our chapter on "Feeding", he will probably get rid of them without dosing, unless perhaps it may be a tape worm. 
If it is thought best to give medicines, there are many well advertised preparations. If these are not available the following treatment will usually get results.

Do not feed him in the evening, but give a liberal dose of Olive Oil. The following morning, give about twenty grains of powdered Areca Nut, in capsules. Follow this in one hour, with at least two tablespoonsful of castor oil. Feed light one hour later. Repeat in ten days or so.

For tape worm, treat as above, except give a capsule of Male Fern, instead of Areca Nut.

The writer some years a go bought a bitch and when she reached us, after a few thousand mi es of travel, she was breaking out with mange, was generally out of condition and had worms. We gave her a little of most everything, but could not rid her of these internal parasites. We also tried several remedies for mange without success. Finally we mixed quite a lot of sulphur and lard and coated her all over with this, for the mange. She promptly proceeded to dress herself, by licking this mixture from her coat. In a few hours she got rid of a surprising lot of round worms and was free of them afterward.

We have given a teaspoonful of sulphur in morning feed for several days, and then followed with Areca nut and secured a tape worm.

Keeping the kennels well swept and the dogs free from fleas will materially lessen the chances from tape worms, still they may come from raw meat or water. Unless the head is removed, they will grow rapidly in body again.

When some of the white flat segments, about three-fourths of an inch in length are passed, it is safe to assume that the tape is present and he should be kept after till gotten. Of course, the dog should have a week or ten days to recuperate, between treatments.

\section{Fleas}

Are a source of great annoyance to the dog when his coat is infested with them and they have the reputation of being great carriers of diseases and the champion conveyors of tape worms. Many things are said to be suitable for their destruction, but the most economical and satisfactory way that we have discovered, is, get a can of genuine Pyrethrum (insect) powder, puncture the 
top in a half dozen places with a very small nail. Put the dog on the grooming table, or his side, shake some of the powder on his throat, holding the other hand over eye and ear sprinkle the side, belly, legs and stern. Then gently brush the powder into his coat. Turn the dog over with his other side up and sprinkle as before. Then have dog stand up and sprinkle from top of head to tail, gently brush this into coat also. Then begin with the muzzle and brush well, in same manner as if no powder had been used and that you were only grooming him. Brush underneath of body and inside of legs. By this time the fleas will begin to drop on the table in a semi-lifeless state and are easily killed. Additional powder may be applied where coat is heaviest and brushed out a minute later. Don't be in too much of a hurry to get the dog off of the table, for the fleas will continue to fall for several minutes. Repeat two days later and at such intervals there after as may be necessary.

Kerosene may also be used, moistening a cloth with it and brushing the coat the right way with it.

Nothing should be used on young nursing puppies, rid the mother of fleas before whelping and see that her quarters are also free from them.

Salt scattered around the houses and kennels, especially in their probable breeding places, and then wet down, is a good way to stop the production of fleas. Tobacco stems used in the same way as salt are also excellent.

When the weather will permit, the kennels should be sprinkled once a day. This will have quite a tendency to keep fleas down, and to keep the dogs cleaner.

\section{Mange}

Not all skin trouble is mange. True mange may be usually detected by quite a disagreeable odor and is different in appearance from other skin troubles. We are frank to say that our experience with mange is very limited and equally as unsatisfactory We never had but one case of it, and we bought that one. Were unable to affect a cure and gave the dog away. We do think though that the treatment herein after mentioned for eczema, will cure many cases of mange and that getting the liver into action will aid materially any other external treatment. 


\section{Eczema}

This is most likely to appear in warm weather and in some instances is quite stubborn. It is said to be caused by indigestion and consequent "bad" blood. Lack of exercise also figures in quite largely.

Treatment should consist of a complete change of diet and conditions, as far as possible. In addition to the treatments hereinafter given, it is frequently best to give two or three good liver pills in the evening, for two or three days and to thoroughly cleanse the kennels and bedding, disinfecting well.

Some kennel men make a rule of giving a teaspoonful of sulphur once each week, to all dogs, as a tonic and blood purifier. We acknowledge with courtesy, the following treatment from E. Blunt, Esq., of England.

\section{Contents of Mixture:}

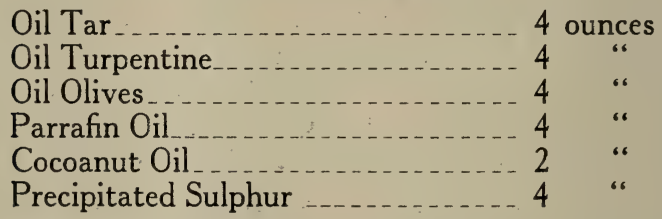

Thoroughly mix and rub well into skin with a brush. Do not wash it off. Do not expose the dog to cold with this on him. Also give one full teaspoon, each, of sulphur and magnesia, in food for three or four mornings and then skip for a week.

We are indebted to Mr. Woodcock, of England for the following ointment, to be used in connection with the internal remedies. mentioned above.

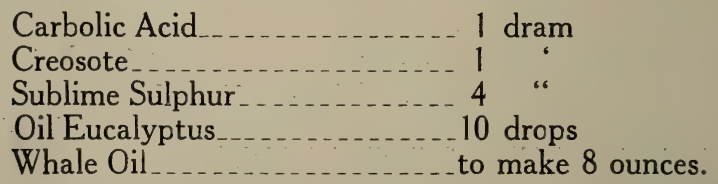

Shake well and apply to eruptions. Keep dog out of dust.

Bathing for skin troubles, or other reascns is undesirable. While an adult may be bathed, puppies ir.der six months should not be bathed. 


\section{Bowel Troubles}

These may assume slightly different appearances. In any instance it is well to give a charcoal, bismuth and pepsin tablet three times a day, and in addition thereto, either two tablespoons of castor oil or some boiled rice, which has been cooked rather dry, Water in which pearl barley has been well soaked, will do instead of the rice and this mixed with boiled milk should be given when the disease has reached somewhat of a troublesome stage. In such cases solid foods should be avoided. Keep the dog quiet and free from exercise.

\section{Wounds when Hunting}

The most satisfactory salve we have ever had, was made by cutting some balsam blisters from the bark of a good live balsam tree, placing them in a small pan with badger oil, then slitting the blisters and slightly cooking the mixture, mixing thoroughly. Then strain the bark out. Bear oil, vaseline or lard may be used with the balsam.

\section{Ear Canker}

The first signs that are usually noticed of this are, the dog scratching at the inside of ear, or carrying his head to one side. By gently pressing and working the lower part of ear proper, a cracking sound may be heard within. Sometimes red sore places may be seen at the entrance to the ear.

\section{Treatment}

Thoroughly cleanse the internal ear with peroxide, or by carefully bathing with luke warm water and castile or reliable medicated soap. Use a sponge or soft cloth and go carefully, as it will likely give the dog some pain. Discover if possible any foreign substance that has found its way there. When dry, or nearly so, place in the ear one half to one teaspoon of powdered borax. On the second day, use borax without again bathing. In severe cases give internal treatment for skin trouble.

\section{Rabies}

Are usually a bugbear. In a recent report by the Superintendent of the New York Society for the Prevention of Cruelty to Animals, we read that in twenty years 150 employees had received about 30,000 bites and not a single case of hydrophobia had re- 
sulted from the bites. The wounds were all cleansed, cauterized and dressed.

\section{Condition Powder}

If others are not obtainable, a very good one may be made by carefully rubbing three ounces of wood ashes and charcoal through a seive. Then add two ounces each of sulphur, powdered coperas and salt. Mix thoroughly and rub through the seive the second time. Give teaspoon in food morning and evening.

\section{Swimming}

If one is situated so that an Airedale can be given a swim occasionally, say twice each week, it will tend to keep him in the best of condition and have him ever ready to retrieve from water. He should be allowed to run, or roll on grass, till dry.

Three have since become first-price winners. 


\section{CHAPTER XII. COLOR AND OTHER POINTS}

We are told that the original color of the body was "Badger grey" or "Bronze Grizzle".

Among many of the fanciers in America the idea seems to prevail that they are going to breed them right away, with the black bodies and get entirely away from the grizzles. This is no easy undertaking, since they are not made of "soft" varieties, but rather of the oldest breeds, and were bred for years with the lighter colored jackets.

Every thing else being equal, the dog with the black saddle will win. But everything else is not going to be equal and while we do prefer the black saddle, we would rather have a real dog than to have color. On this subject, one of the very best judges in Old England, and who has bred them for more than a quarter of a century, writes us. "I am not gone so much on jet black and rich tan. Generally these have a foreign expression to the breed, and very few extra good ones have been this color."

On this same subject, an American who has bred them for many years says. "The grizzles almost always have more terrier quality." While we believe the terrier with the jet black glossy saddle and rich or golden tan; and a hard coat will some day be bred, it can be clearly seen that all are not in favor of it, and that the task is not so easy.

Nor do we believe that the man who breeds them only for show purposes is going to produce him. He may produce a dog having the color and other points, but he is not going to be a Terrier, for, where his ancestors for several generations have been kenneled and shown only, this dog is not going to show the terrier quality that is desired. Work and training is what will keep up the terrier quality and provide the desired expression. A dog without intelligence has an entirely blank face, or expression.

We note recently that one authority calls the breeders attention to the fact that, the standard calls for tan and not red.

In this connection, the narrow skull is not going to be produced with the required intelligence, without work and training. We want a narrow skull, but want something inside of it. 
Most Airedales will go red up the back when a ew years of age, but the standard makes no provision for this. Since this is not considered a serious handicap, it will probably be one of the last faults to be eradicated. A dog that is sufficiently good can usually attain his championship, before he goes off in this respect.

\section{The Airedale Terrier Standard}

Head-Long, with flat skull, not too broad between the ears and narrowing slightly to the eyes, free from wrinkle. Stop hardly visible, and cheeks free from fullness. Jaw deep and powerful, well filled up before the eyes, lips tight. Ears V-shaped with a side carriage, small but not out of proportion to the size of the the dog. The nose black. The eyes small and dark in color, not prominent, but full of Terrier expression. The teeth strong and level.

Neck-Should be of moderate length and thickness, gradually widening toward the shoulders and free from throatiness.

Shoulders and Chest-Shoulders long and sloping well into the back, shoulder blades flat. Chest deep, but not broad.

Hindquarters - Strong and muscular, with no drop. Hocks well let down. The tail set on high and carried gayly, but not curled over the back.

Legs and Feet-Legs perfectly straight, with plenty of bone. Feet small and round with a good depth of pad.

Coat-Hard and wiry, and not so long as to appear ragged It should also lie straight and close, covering the dog well all over the body and legs.

Color-The head and ears, with the exception of dark markings on each side of skull, should be tan, the ears being of a darker shade than the rest. The legs up to the thighs and elbows being also tan, the body black or dark grizzle.

Size-Dogs, 40 to 45 pounds weight. Bitches slightly less.

(Undersized specimens are to be severely handicapped-Author).

Scale of Foints

Head, ears, eyes, mouth

Neck, shoulders and chest, ......... 10

Body _... .

Hindquarters and stern............. 5 
Legs and feet . . . . . . . 15

Coat _........... 15

Color _....

General character, expression . . . . . . 15

Total ............. 100 


\section{CHAPTER XIII.}

\section{SHOWING}

In these days of dog evolution, or breeding dogs for prizes and profits on an extensive scale, the "handling" of dogs in the show ring has developed into an art. In this way, it is of paramount importance that fanciers who elect to follow the pursuit of dog showing, whether as a hobby supplementary to their daily toil or avocation, or whether as a profession, to which dog showing lately developed, should post themselves up in the requirements of the show ring which are essential to success. It is not enough to possess a good dog, for it is often the case that a moderate dog well tutored and "handled," will beat a better dog indifferently shown.

Whatever a dog may be at home or before going into the ring, or when he comes out of it, it is what he looks like at that critical moment when the judge's eye is on him, and when the judge decides upon the relative merits of the dogs before him.

The writer has tied a great many ribbons on horses and other live stock and has placed first on an animal that might be entirely out of it the next day. Again we have seen those that were out of it today, come back and win first tomorrow. The same is true in judging dogs. Therefore it is necessary to have the dog so that he will show for all that is in him and at all times.

Since there are so many different temperaments in them, it is not easy to have them do this. Schooling and educating is what counts.

To make a show dog, one should begin on the puppy when he is quite young, getting him out frequently and so that he will stand up and be ready for anything that happens.

When he is a few months old, put him upon the table and teach him to pose, by placing his legs in good position, the hind ones a trifle back; one hand under the base of his jaw and the other holdng his tail up. Talk to him and go easy with him. When you have given him a short lesson, thank him for it and give a little longer lesson a few hours later. At the conclusion, each time encourage him and in a very short time he will pose after your hands are removed. 
When he is out on the leash and sees another dog, encourage him a little by telling him to "watch him", or something similar. Let him think that he can "lick" any dog living, but don't let him get to the dog, being a puppy, one snap might take all the "snap" out of him.

Another system is to use liver. Take two or three pounds of beef liver and boil it for half an hour, then place inside the oven and bake the same length of time and have it entirely dry when finished. Cut into cubes the size of dice, take a handful in your pocket and take the dog entirely away from all others, and from anything that will distract his attention. Take lead in one hand and a piece of liver in the other and tease him, by letting him nip at the liver, without giving it to him. Hold him back with the lead. Again throw the liver on the ground ahead of him and let him pull hard to get it. Stop this part of the education as soon as he gets interested, for pulling on the lead will throw the elbows out and cause him to stand awkwardly. The idea is to get him to stand entirely still, leash held loosely and he at attention all the time, with you motioning as though you were going to thorw the liver to him. It is best to take him out on an empty stomach for these lessons and occasionally let him get a piece of liver till all is consumed.

It is quite difficult to tell one how to show a dog, they must learn it. One thing is very important, when you are in the ring, keep one eye on the judge and two eyes on your dog, never mind about the other fellow's dog, He is handling that one.

It is by far best to have your dog show on his "metal" if possible, and if he does this and wants to whip the other dogs, you should let him go quite a ways in that direction, always, of course, being careful not to make yourself a nuisance to the judge.

The very best way for one to learn to show a dog, is to watch a person who is an expert and see just how it is done.

When in the ring, one should at all times deport himself as a gentleman and sportsman, while endeavoring to get all that is rightfully coming to him, he should not try any tricks that will damage another.

The judge will stand facing the block and when your dog is called to be closely looked over, take him around the ring to where he is facing the judge and then straight to the block.

While it may be well to lift him up by the leash and set him 
down squarely on his feet, that his front will appear at its best, it is all wrong to hang him up all the time. It may be necessary to have a taut lead on him most of the time, but don't pull his throat, ears and neck all out of line by hanging him up. No judge who is familiar with the game, is going to be fooled in this way. He will learn what kind of a front, pasterns and feet the dog has, before he ties the ribbons.

Don't work the dog when the judge is busy with others, that will only tire him and cause him to be sluggish when the critical time arrives.

Valuable dogs should not be left for the average show attendant to water and feed either look after your dog personally or pay some competent person to do so. If he is a light eater it is well to have some meat for him, as he will probably not eat the biscuits, and will become too gaunt. On the other hand he should not be too full, when taken into the ring.

Most Airedales should be shown quite heavy in flesh, especially one that is inclined to be long in back.

It is folly to make a pet of an Airedale that is to be a worker or show specimen. That is, we mean, do not be constantly pet-

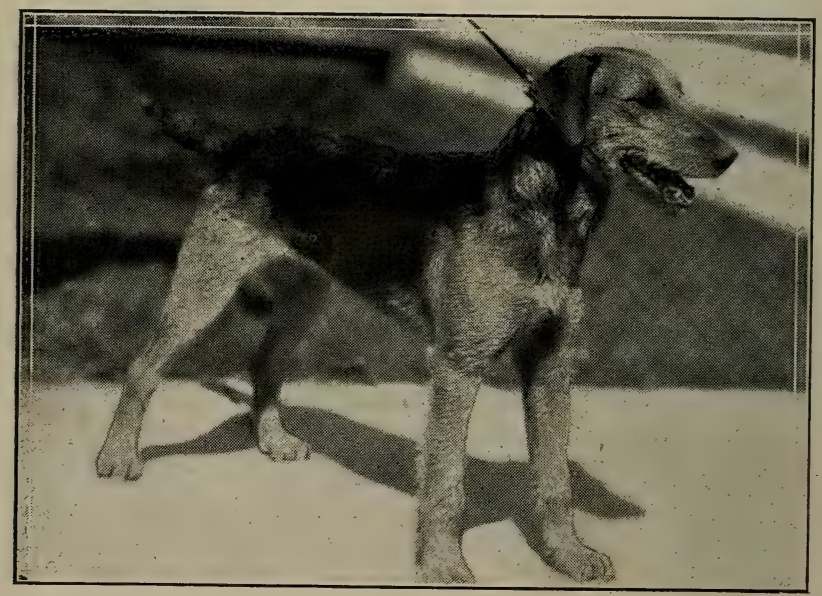

A Young Bitch of splendid type. 
ting him so that he looks for it all the time and comes around and rubs against you or lies down, to be petted. He will have no snap in him if this is done. Let him be up and coming, ready for a foot race with you or to kill the neighbor's cat, whip his dog, or any old thing, just so he is on his feet and alert.

\section{Trimming}

No difference how good he may be, all of them need some trimming to get them in condition for showing. Those with correct coats need very little trimming, this is entirely permissable and is generally practiced. The object being to bring out the strong points, and when necessary, to have a good new coat at the time of the show. Like showing, stripping must be learned and there is room for no little skill in properly doing it.

We know of three ways to remove the surplus or dead hair. By using stripping comb; by plucking with thumb and finger; and by using a knife that is not too sharp, and catching the hair between the blade and the thumb. Scissors should not be used, for they will leave marks that show the dog has been stripped, will not remove the dead hair and no decent work can be done with them.

If a new body coat is needed, this part of the dog should be stippped about two months before the show. Those who grow their coats rapidly will not need quite so much time, while those who grow slowly will require fully this length of time. The finishing of the body, removing the surplus hair in the flanks, on the belly at the waist, (this will deepen the brisket,) and of the sheath, may be done about a week before the show.

The head, neck and shoulders, ten days to two weeks only are required to grow a new coat. In some instances the skull will require only a week or ten days.

The feet should be trimmed, with small scissors, three weeks before showing, removing all the hair around them at a point where they come in contact with the ground and just above this point. The intention is to have them appear small and well padded. If the dog has been kept on soft ground and his nails are long, these should also be cut, but not close enough to bleed. His nails will be conditioned and his feet tightened up and improved, by exercising on paving or hard road. 


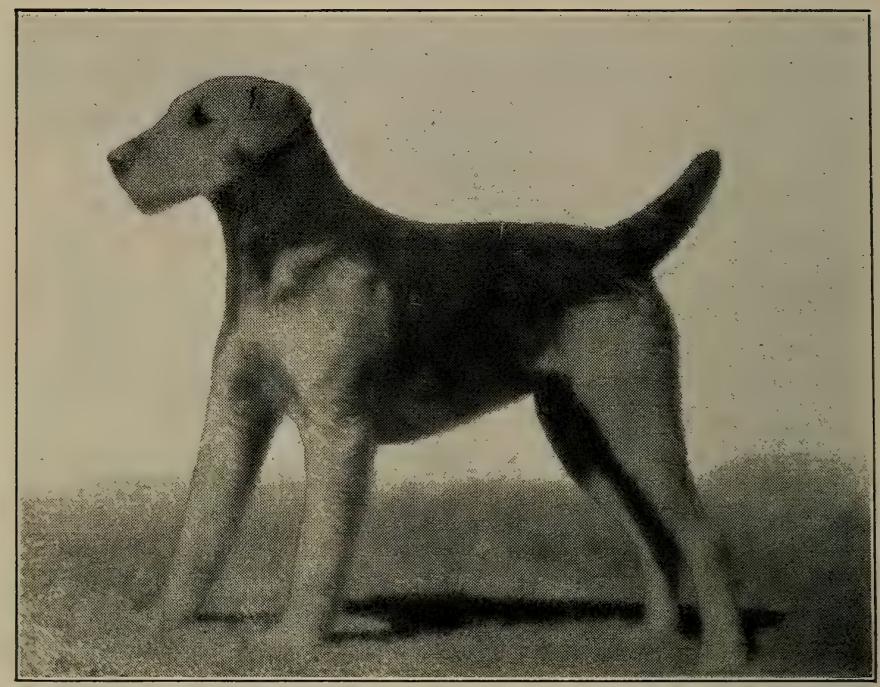

Hy-Born Belle 196014.

"Hy-Born Belle" that the author thinks is as great as has yet been produced in combining show points and extreme Airedale qualities.

Excepting the feet, no trimming is to be done below the elbows and hocks, nor in front of a line drawn around the head at the eyes. In all cases the trimming is to be done so that the longer hair graudates evenly to the shorter hair, and so that the tan will meet the darker coat properly.

In trimming the head, the whiskers are left untouched, while the skull and throat are stripped quite closely, the object being to have the muzzle and foreface as strong as possible and the skull narsow. Proper trimming of the throat and skull lengthens the appearance of the head. A perfect head would b in the shape of an oblong square, whether viewed from in front or from the side, the muzzle being square and as broad as the skull, the under aw being straight, also top 1 ne of the head, except a possible fullness at the eyes. The ears should be well trimmed and if at all heavy, especial a tention should be paid to the edges, that the ears may appear as small as possible.

The tail may be lengthened an inch by leaving the long hairs 
entending beyond the bone; or it may be shortened by removing these and slightly pointing the tail, that the end may appear properly, at the very end of the bone. Usually the top of the tail should be about level with the top of the head. The hindquarters may be broadened in appearance, by making the tail smaller.

Dogs that are short on furnishings on the foreface and front legs, will most likely have more when two years of age. In fact, most Airedales are at their best, as to show points, when around two years old. Slow finishers are not made up until this age is reached.

It is very rare indeed to see a straight hard coat in company with plenty of whisker, yet this is what we strive for-not too much whisker, but enough. As a rule, an abundence of whiskers accompany a soft coat.

For two or three weeks before showing, the dog should be kept kenneled and given most of his exercise on the lead, that he may learn to be at his best when on the lead. An hour may be spent profitably morning and evening, in this way.

During this time he should be thoroughly groomed each time before being taken out, brushing for five to ten minutes and hand rubbing for the same length of time. The coat may be much improved by placing a raw egg inthe food once or twice each day.

When you are defeated in the ring, take your medicine and carefully study the dog that beat yours and learn how to beat him next time. 


\section{CHAPTER XIV. \\ SELLING AND SHIPPING}

If one is in the business for profit as well as pleasure, or is even planning to have his kennels pay their way, selling is a very importan matter for him and in some instances leads the breeder into injurious paths, that of selling some inferior dog or puppy for more than it is worth. This, in the long run will not pay, if one intends to stay in the game and feels like looking every man squarely in the face. It is much better to give each customer a little more for his money than he expects, than to get a little more money than you give value There is no better ad than an entirely satisfied customer. When your business is conductcd along these lines and you frequently hear of persons, of whom you do not know, saying, "You may try where you please, but when you get through and write to the 'Reliable Kennels' you wil buy there and get what you are look ng for, if you want a good cne and your money's worth", then will you feel that ycur efforts have not been in va $\mathrm{n}$ and that you are reaping some reward. This has happened frequently and will happen to any one who breeds them right and sells them worth the money.

To do this, what is necessary? You must have the stock to breed from; you must know the breed and how to mate them for results; and you must study and be able to know what you are offering. Furthermore, you must watch the market both as to values and as to changes in fashions and other conditions.

If you wish to improve your stock, it is best to hold onto the good puppies that promise to make what you like, than to even sell them for a rather long figure, and be unab'e to replace them.

Puppies that are intended for sale, should be so $d$ for what they are worth at the time, not what they may be worth later. That second value may come and it may not.

The seller must know his stock, and if he will take the best of care of it and strip it up some before shipping and brush the coat enough to have it in good condition, the buyer will be better pleased than if a superior dog is sent, that is out of cond tion. If the dog should be out of condition at the time it is cffered, the buyer should be informed of it. The distance of the custcmer from the seller, should not enter in to the consideration at all. 
This old world is getting smaller every day and distance is be.ng constantly shortened.

The man who knows a good dog and wants a good one, will be willing to pay a fair price for him but the ordinary buyer is mainly concerned with general appearance and attractiveness.

Stock that does not come up to the standard set by the breeder and yet is intelligent and good for utility purposes, may be sold un-named and without pedigree. Yet if your breeders are good and have been bred for generations along these lines, there will not be much if any need of such sales. They may come in a case where one has bought a bitch in whelp, or even one and bred her to his own stock. If some of her ancestors were bad, no difference how good your stud is, some of the puppies are liable and most likely to "breed back", and it is these that may be sold as suggested.

\section{Shipping}

Judging from the crates that we see dogs shipped in some times, it would seem that the shippers were more interested in enabling the express company to declare large dividends, than in the sale of dogs and his customers welfare. The writer bought a 40 pound bitch that was crated at 125 pounds. when she could have been crated at $i 5$ to 85 pounds. No need to pay ten to fifteen cents per pound on unnecessary lumber.

The ignorance that is displayed in many ways in shipping, by persons who should know something about it, is absolutely astounding. This is one point that gets on the writer's nerves, but we shall refrain from "roasting" such persons-though they really need a li eral roasting - and will try to tell how we think shipping should be done.

Don't ship a dog so that he will arrive at his desitnation, or at some branch junction, on Sunday and be compelled to remain in the crate a day longer.

Ship as promptly as possible after the order has been received, and if possible, advise the customer in advance, when to expect his purchase.

\section{The Crate}

A slightly larger crate is required for long shipments than for shorter ones and if the dog is to remain in the crate more than twenty four hours, a false or inner bottom should be put in and 
fully arranged for drainage. There should be a space of fully a half inch between this and the outer bottom of crate. This false bottom should be securely fastened, for fear the crate gets upset by accident, or is thrown over by some human who should be in an iron crate, and the loose bottom lodges and cramps the dog. The crate for a grown Airedale should be 28 to 31 inches high, 18 to 22 inches wide and 36 to 42 inches in length. Roof should be tight to protect from sun, rain and drafts. An inch and a half to two inch space should be left on each side, immediately under the roof, the length of the crate. This will provide sufficient circulation of air and avoids drafts, as well as having ventilation shut off by other merchandise in the cars.

If the dog is going any distance a hinged door should be made at one end of the crate, that the messenger may the more conveniently feed, water, clean out the crate and give the dog a little exercise.

Collar should be placed on the dog and a chain fastened on the outside of the door, in a very convenient manner for removing. The kennel name of the dog should be placed on the top of the door so those handling and receiving him, may call him by his familiar name.

A vessel for water should be conveniently arranged, yet so fastened that it will not be constantly turning over or spilling. Sufficient food should be placed in a sack, one side of the top of which, is securely fastened to the end of the crate, The best rations for the journey, are dog biscuit and corn bread. The latter should be cooked with some grease in it.

Whatever may be the size of the dog, one of the most necessary things to be considered in crating, is, that he has enough room for his head to be up at full height without hitting the roof. We have seen a puppy that was unable to get his head up for a week, after being shipped in a low crate.

Good stiff straw makes the best bedding, and allowance should be made for it breaking up and being removed.

Always teach the dog to lead before shipping.

At the present time, the express rate on dogs is one and one-half the merchandise rate. Dogs returning from shows carry threefourths merchaniise rate.

In some cases it is to the sellers advantage to advise the prospective buyer, what the probable express charges will be. 
Carriers are obligated to deliver at the end of their routes, dogs, in the same condition as received, except in case of damage resulting in some unavoidable manner, such as an act of the dog.

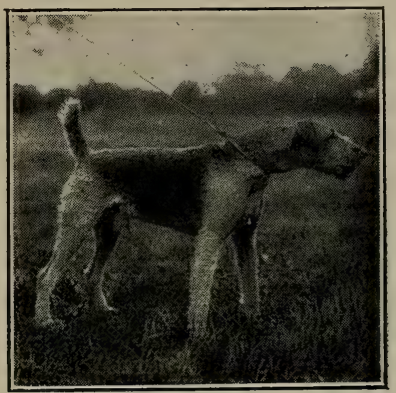

Champion Midland Royal 


\section{CHAPTER XV.}

\section{ADVERTISING}

This is really a personal matter and many things enter in for consideration and no difference how conservative the beginner may be, he is sure to feel that he has thrown away some money in certain advertisements. Yet in this he may be mistaken, for results may come in an indirect manner and long after the ad is forgotten.

Do not expect your public announcements to do it all. Right here is where many beginners come to grief. They forget that a pleased customer is the best advertisement. Your press statement is merely a sort of intr sduction after all, just bringing buyer and seller together. It may create the new customer, but it does not take care of him. It should never be forgotten that the building of a good kennel business depends as much upon the way the new customers are treated as it does upon getting them the first time. First be sure you have the goods to deliver; and then let your values, service and courtesy be such as to make people want to buy your stock and tell their friends about it. That is good advertising for you, better than you can buy in any paper.

No difference how good may be your stock, it will not sell itself. There are many ways of advertising, such as constantly telling people what you have: having dogs out where they may be seen; showing; and the many uses of printers ink. Having Airedales that will work and surprise "the natives" is also very good. To have every one in your local town or city, know and think well of your stock is one of the best means of advertising, since every inquirer will receive a favorable report. Also, when you have attained a "rep" your friends and the press will gladly advertise you in a way that money will not.

Remember, too, that printed matter has a personality of its own, and see that your kennel cards and circulars are not allowed to malign you or your stock. Good printing, paper and engraving all have considerable advertising value, and are well worth what they cost. The very letter you write is often the basis upon which a distant customer builds his opinion of the quality of your produce; and y ur kennel literature stands for yourself to people 
who have never met you. Take time therefore over your circulars and stud cards; and personally makes sure the proofs are correct before printing.

Few things tend to inspire confidence in a kennel more than continuous, temperately worded and truthful advertising,.

It is up to each individual to decide and to ascertain what periodicals are the best located and best suited to his stock. If you have the quality in stock, distance is not to be considered to any great extent, but there must be something in your announcement, and in the follow-up that will carry the necessary weight. When an inquiry is received it is up to you to handle this in a way that will bring results. Cuts of at least some of your stock will aid materially.

The editors of most of the kennel papers will be pleased to aid you in getting up copy for their respective papers, and their experience in this line is worth considering.

Advertising does not always bring immediate returns and if one has the stock, it is best to keep eternally at advertising and the results will come.

Cheap-or inexpensive-advertising is most likely to reach persons who are looking for cheap stuff. The cost of an ad that will sell sufficient stock is much less, than is an inexpensive ad that sells nothing. However there is no good judgement in the beginner putting large sums into advertising, till he has learned where to place such ads, and equally important is his ability to

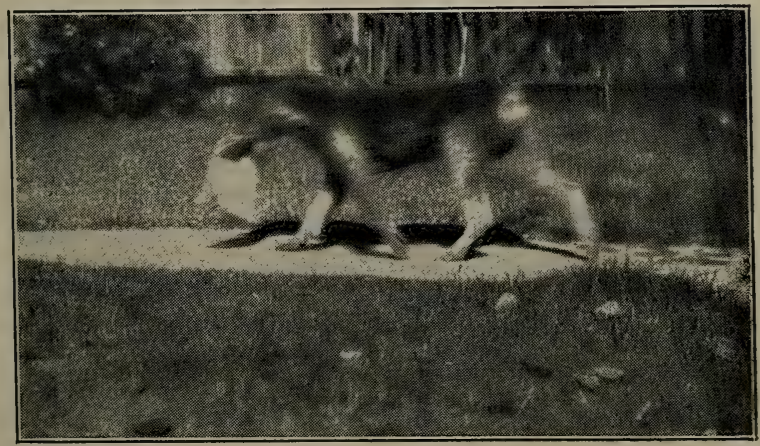

Three months old puppy bringing in the morning paper. 
know his stock and the Airedale game in every detail. This may only be had by experience.

Get your stock; know what you have; advertise honestly and conservatively; treat every inquirer well, whether he buys or not; keep eternally at it and the results are sure to come. 


\section{CHAPTER XIV. \\ MISCELLANEOUS}

This chapter is intended to contain some things that have occurred to us after the writing of the foregoing ones and some other "random shots."

The dogs health and happiness depends on the good treatment you give in food, kennel and a display of your affection.

Rolled oats cooked in milk, is splendid food for a bitch in whelp. Cooked vegetables, carrots, turnips, onions etc., should be fed also once or twice a week, but the vegatebles should be discontinued for ten days or two weeks, after the puppies arrive. Rolled oats cooked in milk, dog biscuit broken and fed in broth, cooked and raw lean beef, should be the principal food for the nursing bitch. Table scraps will be much enjoyed by her at any time.

Did you ever stop to think that all the pay the dog realizes he gets from you, is your displayed affection As to food and a place to sleep, he thinks these are coming to him, but when you let him accompany you or be near you, or caress him and thank him for some act of his, then he thinks he is being paid and that is all the coin he wants. This is quite inexpensive to you, so let him have a sufficient quantity to satisfy him, but not sufficient to cause him want to too much caressing.

A choke collar may be used on some Airedales to advantage, but as a rule, tocultivate their fidelity is sufficient.

Don't put pepper in the food at all times, only when it is thought necessary to free them from worms.

A piece of rope a few feet long, knot on each end, will provide much amusement and exercise for them. Also will limbs form trees if piled up so they may climb and jump over them and crawl under.

A medicine chest should be provided and such remedies as are needed, kept free from dust and where they may be easily found.

Powdered borax should be frequently sprinlked in the retainer in which the droppings are placed and on the droppings, to kill flies. Fly traps or fly paper should also be used.

Nother and puppies should have a wire screen in summer, to protect them from flies and other insects. 
Uneaten food should not be left for an attraction to flies.

"Come-back" bread obtained from restaurants, soaked in broth and to which is added some bran and rolled oats, provides an inexpensive appetizing meal.

Frequently a bad feeder may be made to eat more by placing another dog in the kennel and feeding both from one vessel.

Also pretending to take the food from him, will frequently cause him to want it.

Clean fresh water doesn't cost much and you like it for your own consumption, don't you?

Same is true of the food dishes.

Cod liver oil may be put in food for puppies, to an advantage. Concrete may be used extensively in constructing kennel buildings. Is easy to cleanse, prevents drafts and is most sanitary.

Some tell us that a collie will quit, when driving stock in warm weather. A reliable Airedale will not.

A brainy Airedale will quickly adapt himself to most any vocation and surroundings. Whatever his master does he will want to aid. We have seen them try to help catch minnows and know of one that will carry a lighted lantern to the barn for her master. when he returns home at night. The writer owns one-she is not for sale-so we are not advertising her, that can catch two mice in her mouth at one time and the third with her feet. She stops poultry fights, points quail, retrieves from land or water, will fight a cyclone and is a splendid companion. She is also a winning bitch and the dam of the dog shown with the police sergeant.

When we wrote the chapter on proper matings, we did not expect to own Champion Midland Royal, but since what was written, is thought by us to be absolutely true, we will not change it.

Finally: We mentioned to the business manager of one of the kennel magazines that we were thinking of getting out a book descriptive of the Airedales in which we are so interested, and said business manager suggested that a book on the breed in general, be written instead. So if we have failed to benefit you. dear reader, he is the one to be censured.

If we have been of any aid to you or the noble breed of dogs, in whose interest this effort is primarily made, or any other breed we shall be pleased and will pass that pleasure along to the said business manager. 


\section{INDEX TO ILLUSTRATIONS}

Companions,

Out with the sergeant, $\ldots \ldots \ldots \ldots \ldots$

Hy-Born Defiance and "Tom", _ $\quad \ldots \quad \ldots \quad \ldots$

Haphazard, a, - _ _ _ - _ _ $\quad 17$

Model, .. _ _ _ _ _ _ _ _ 20

Ch. Clomnel Rough and Ready, .. _ _ _ _ _ $\quad$ _ 30

Feeding time, - _ _ _ _ 36

A promising litter, _ _ _ _ _ _ _ _ 48

Bitch and lion skin, $\ldots \ldots \ldots \ldots+\ldots$

Child, lynx and Airedale, _... $\quad \ldots \ldots \ldots \ldots$

Hy-Born Lady and quail, _ _ _ _ _ _ _ _ 57

View of kennels, _ _ _ _ _ _ 60

A good type of house, _ _ $\quad \ldots \quad \ldots+\ldots \ldots$

A splendid young bitch, _ _

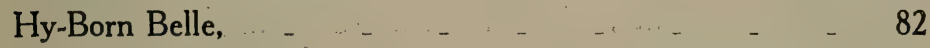

Show and Utility type, _ _ _ _ _ _ _ 82

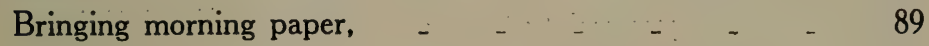


Achievements to be attained.. 58 Adaptability, ..9, 10, 13, 13, 51, 54

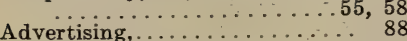

All round good ones, . . . . . 16, 40

Areca nut, ............. 48, 70

Aristocrat, ............... 13

Bargains in, ............ 15, 19

Bear hunting, .............. 57

Bedding,............... 61

Beds for bitch and puppies. 36,91

Beef; raw,............. 23, 37

Bell shaped muzzle,... . . . . . . . 39

Bitches, age in use,. . . . . . . . . 32

Bitches, age to mate, ........ 32

Bitches are cheaper,......... 22,44

Bitches in pedigree of stud, . . .27

Bitches in use, keeping, .....22, 27

Bitches, retaining good ones.22, 35

Bitches, utility of, ... . . . 22, 32

Bone, growing, (see Calcium Phosphate.)

Bones,................. 29

Bones, causing fights,........ 25

Bones, chicken,............. 23

Bowel trouble,.............. 73

Brains, $\quad 16,41,50,58,75,75,92$

Bran, ............. 23, 24

Bread,................. 24, 25

Breaking to auto,........... 54

Breasts, care of, . . . . . . . . . 45

Breeder's Assistance, ... 20, 21, 39

Breeder's reputation and judge. ment, . . 20, $22,39,40,84$

Breeding for convenience,...... 40

Breeding for nothing,......... 18 Breeding, pleasure and bene-
fits in, . .

Breeding, services, ... . . . . 33, 34

Breeding to winners, . . . . . . . . 38

Breeding vs buying............ 15

Breeds used in making........ 9

Brood bitch and puppies bed, .36, 91

Brood bitch, average number of litters..............

Brood bitch, care and feed, . $31,32,34,34,35,36,37,45$

Brood bitch care of breasts, .... 45

Brood bitch, controlling coat, 32,68

Brood bitch, continuous mating 32

Brood bitch, contracting distemper,................

Brood bitch, effects of educations,............ 32, 34

Brood bitch, diversion for,

B.......... 34, 37, 49

Brood bitch, feeding while in whelp,.........24, 29, 34

Brood bitch, fleas, ............. 34

Brood bitch, free from worms, 32

Brood bitch, frequency in use. 32

Brood bitch, frequent large lit-

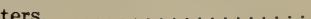

Brood bitch, giving calcium phospnate, ............

Brood bicch, going out of use, $\ldots \ldots \ldots \ldots$ ss, 34

Brood bitch, good necessary,.. 31

brood biten, large,.......... 31

Brood biten, 1aeal,...........31, 32

brood biten, laxative before whèlping,............. 34

Brood bicen, milk vs cows milk,............. 45,48

Brood bicen, period,........ 33

brood biten, period of gestation,................. 34

Brood bitch, safety,........33, 34

Brood biten, selection of, ...... 31

brood bicen, snelf when nursing, .............. 37,49

Brood bicen, the,............ 31

Brood bicen, time in whelping, 35

brood bicen, value of in mating,................ 31

Broou witen, working of, . . . 32 , s4

Brotn, ruaking,............ 23

Brotn, sour, ................... 25

Brotn, sour to bitches,........ 25

butter milk, . ........... 24

Buying,....... $19,20,21,22,27$

Buyın bargains, .......15, 19, 20

Buying, triend's advice,........ 19

Buying, object in, . . . . . . . 19, 22

Calcium Phosphate,.....34, 45, 46

Camping, how to feed,........ 26

Cats,..................... 58

Cin: vionmel Rough and Ready 28

Ch. Crompton Ooring,........ 39

Ch. Mialand Royal,.. $39,40,43,92$

Chicken bones,............ 23

Chilaren's protectors, .... . $10,53,58$

Choke collar, use of, ......... 91

Chorea,.................. 69

Cleansing, ................ 21

Climates, adaptability to ...... 59

Coat, the............... 83

C. 0. D. . . . . . . . . 22

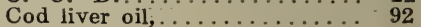

Color at birth,............. 18

Condition powder, .......... 25,74

Constitpation,............... 49

Color and other points, . . 16, 44, 75

Copperas,................ 25

Corn meal, ................ 24

Correcting faults, .............. 38

Cows, lesson from,........20, 40

Cows milk vs bitches, . . . . . . 45, 48

Crate, the shipping,.......... 85

Culling puppies,...........43, 44

Cutting tails,.............. 44

Demand for $. \ldots \ldots \ldots \ldots \ldots, 16$

Dew claws,................. 44

Digging, advantages and ills,... 61

Digging, how to stop,........ 61

Diseases,............... 65 
Disenfictants, . . . . . . . 63, 64 Disposition; producing, $.41,49,78$

Dispositions, ............9, 10

Distemper,. . . . . . . . . . . 66

Distinction in owning, ......13, 16

Docking, . . . . . . . . . . . . . 44

Dog biscuit, . . . . . . . 24, 91

Ear canker, . . . . . . . . . . . 73

Eczema, . . . . . . . . . . 72

Educating breeding stock, ...... 41

English breeders,. . . . . . . . . . 29

Exhibition matings, .......... 38

Exercising, ........10, 23, 24, 74

Express companies as agents, 22

Express companies risks,.22, 86, 87

Fad, not a, . . . . . . . . . 13

Famous dogs, breeding from 38,40

Fashion, changing of, ...... 42

Fatten, how to,............. 25

Feeding, .............23, 92

Feeding, abrupt changes in, . 23

Feeding, bran etc.,.......... 24

Feeding large kennels, . . . . . . 23

Feeding puppies, ............ 45

Feeding puppies, bad doers, 46, 92

Feeding, summer and winter, 24, 48

Feeding to avoid worms,...... 25

Feeding to suit dog,.......23, 24

Feeding . when camping, ...... 25

Feet, tender, . . . . . . . . 21

Fighters . . . . . . . . . . . 46, 49

Fits from hunting, . . . . . . 58

Fires, avoiding, ............. 62

Fleas, . . . .

Flies, destroying, . . . . . . 91, 92

Foundation of, . . . . . . . . 9

Foster mother, (See mother, foster)

Fullers earth, . . . . . . . . . . 21

Future of,............. 41

Garlic, . . . . . . . . . . . 23

Giving medicine, . . . . . . . 65

Guards, as, ...........11, 58

Gun, kind to use.......... 65

Haphazards, . . . . . . . . . . . 42

Haphazard, crime of breeding 42

Haphazard, the proudced,.... 17

Hearing, ................ 11

Hens, lessons from, ........40, 42

Hospital, . . . . . . . . . . 61

Hot foods, . . . . . . . . . . . . 24

Hunters, ................. 58

Hunting when soft,....... 58

Importing, ............ 21

Intelligence, (See brains.)

Intensifying faults, .......... 39

Invalid persons, profit, .....42, 58

Investment, as, ............ 13

Kenneling, .......... 46, 59

Kennels, cleaning. . . . . 61, 62, 63

Kinds, three,.............. 14

Lady's companion, ............. 9

Large specimens,......... 31
Light eaters, . . . . . . . . 10, 23

Line breeding, . . . . . . 39, 40,42

Lion hunting, . . . . . . . . . . $5,4,57$

Litters, number composing, . . . 33, 35

Litters, number desired in,. . . . 35

Loafers, breaking,........... 54

Luchorhea,................ 33

Mange,............. 71

Mating for convenience, . . 16, 17, 38

Mating young to old....15, 16, 38

Mating, object in, ......... 38

Medicine, giving, ........... 65

Meat, raw,............ 45

Midlings, .............. 24

Mother, foster,....... 3536,43

Mother loss of, ........... 48

Mother, shelf for, ......... 47,49

Mother's condition affects pups, .............. 45

Mothers encouraging fights, ... 49

Mothers good,...........35, 49

Name, the, how derived,...... 9

Neck, long arched,.......... 65

New blood, ............... 39

Nose, the............... 10

Not eating, $\ldots \ldots \ldots \ldots \ldots \ldots \ldots, 25$

Novice breeders, ........... 19, 39

Nursing vs dosing, . . . . . . . 65

Object in breeding,......... 38

Obstacles in breeding,

One-man-dog..........13, 21, 54

Ordering, how to,.......... 22

Origin, when, where and by whom, ............ 9

Orphans, ............... 48

Otter hound, the ............ 9

Overshot,............... 48

Pepper, use of, $\ldots 23$ 25, 26, 46, 91 Pepper, not for puppies,...26, 46 Pleasure in, ............15, 16, 51 Pneumonia, ................ 68 Pneumania, preventing, . . . 62, 63 Poaching, first used for, . . . . 9 Pointing quail, ............ 11, 56 Police dogs, as, . . . . . . . . . 11

Popularity,............... 13

Poultry, acquainting with, . . 58

Poultryman's aid,............ 11

Poultry killing,............... 58

Potatoes, feeding, .......... 23

Prepotency of sire, .............38, 40

Present dogs high class, . . . . 39

Printing, good........... 88

Profits in, ............. 32

Punishing,................ 51

Puppies, dead at birth, . 34, 35, 44

Puppies, number in litters, 33, 35

Puppies raising

$$
\ldots 29,31,34,35,3843,48
$$

Puppies, retaining good ones, 43,84

Puppies, teaching to lead,.... 53

Puppies, selecting, . . . . 35, 43, 44

Puppies, white on,........... 43

Puppies, young, regulating bowels, .........36, 37, 45 
Quail pointing,..........11, 56 Quality and utility ones, (See Show and Utility)

Quality and utility, breeding of $\ldots \ldots \ldots \ldots \ldots \ldots, 41$

Quiet ones, game,............50, 51

Rabies,............... 73

Raising puppies, .......... 37

Ranch, uses on, . . . . . . . 11

Ratters, as, ............ 11

Real sires few, .........27, 38

Rearing on people,........ 55

Receiving,............... 21

Recreation from handiing, ... 15, 42

Rejecting on a:rival,......21, 22

Reputation as breede:, (See breeder $\mathrm{s}$ reputation.

Retriever, as, .....11, 53, 54, 55

Reward of breeder,........15, 42

Rolled oats,.........24, 46, 91

Running away from home,... 54

Running rabbits and deer,.... 56

Scale oi points, ......... 76

Selecting puppies, ......35, 43, 44

Selling,.............. 18, 84

Sex, controlling,........... 33

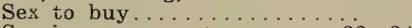

Services, one or two,......33, 34

3hade,................... 62

Shipping, . . . . . . . . 85

Show and utility class, $16,40,88,92$

Shooting over,........... 55

Showing,................. 78

Showing continuously, . . . . 30

Show type,............15, 78

Sires, real ones, ........27, 38

Skuil, nacrow,............. 75

Sleeping quariers, dry, ....... 59

Slow maturers, ............. 46

Soup, sour to bitches, . . . . . . 46

Standard, the ............. 76

Standard, correcting to,... 38, 39

Stuck drivers, . . . . . . . 11, 58, 92

Stomach, eare of . . . . . . . . 25

Street, training for . . . . . . . . 34

Stripping,............28, 81 .

Stud, age for use, ........ 29

Stud, controlling, ......27, 28, 29

Stud, free from worms, ....... 30

Stud, general management, .............27, 28,29, 30.
Stud, will injure voungsters, 27, 28

Stud, selection of . . . . 27, 32, 43

Stud, punishing, .........28, 51

Stud, puppies for fees, . . . . . 30

Stud, will be boss, ............ 27

Stud, value of pedigree, . 27, 29, 38

Students of human nature, . 10, 53

Sulphur,..............25, 70

Table, feeding from, ....... 25

Talking to .............. 54

Teaching differens languages, .. 56

Teeth,................. 48

Terrier quality, . .28, $31,51,49,75$

Three kinds, ............ 15

Toppers, breeding,........15, 16

Toy, treating as, ..........23, 80

Top not yet reached,....... 41

Trailing, ................ 10

Trailing, not givisi tongue,... 9

Training,............29, 48, 51

Training for street,........... 54

Training puppies,..........48, 53

Traits, ..................

Trimming, ............... 81

Trotters, lesson from, . . . . 20, 39

Usages, varied, . . . . . . . . . 42

Undershot,............... 48

Values of,$\ldots \ldots \ldots \ldots \ldots \ldots 20$

Varmint killers,............. 11

Vegetables, ,eeding,.......... 91

Vessels, feed and water, ....... 25

War, uses in, ........... 11

Washing.................. 55

Water, drinking, . . . . . . . . 25

Water vessels, ............... 25

Waterside terrier, first called. . 9

Weaning puppies, ......... 49

Weight of growizg puppies,... 46

Wester $u$ bred ones, .......... 41

Whelping quarters, . . . . . 35, 36, 37

White bread, ............25, 92

White on puppies, ............ 43

Worker, a .............40, 41

Working dogs need food,..... 25

Worming puppies, . . . . . . 48, 49

Worms, frcei. $\mathrm{g}$ om, $\because 6,40 \% 49,69$

Wounds, ................ 73 
Advertising Section

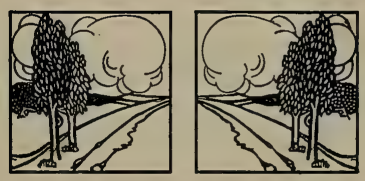





\section{"If its a Bettis Ariedale, it is all right."}

\section{The Home of the Bettis Strain}

of Airedales

Bred for years as Hunters, Companions, Guards and Winners. Combining extreme Intelligence and Quality.

Puppies and grown stock from educated and winning parents usually for sale. Prices reasonable.

In making inquiry, we will thank you to say for what purpose the dog is to be used. We will please you or frankly say we are unable to supply.

\section{HIGH CLASS STUD DOGS AT MODERATE FEES}

\section{HY-BORN KENNELS}

2227 White Avenue, - $\quad$ Fresno, Californis.

Cable address: "Bettis." 


\section{The name of \\ Champion

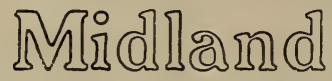

Is known wherever the Airedale is known.

As a winner, sire of Champions and Winners, and having his blood appear in most of the best, he is unique.

As the sire of dams of Toppers he has surpassed them all.

A dog of wonderful constitution, as frisky as a puppy and and leaves behind him in England puppies that will go to the front.

A sire that gets dark eyes, splendid ears, hard coats, most beautiful expression, and size, with Terrier Quality. Has done more to narrow the skulls than any other Airedale.

Fee, for approved bitches - - - $\$ 40.00$

A few select bitches from a distance of one thousand miles, - - - - - - $\$ 25.00$

Bitches must be prepaid and draft must accompany them in all cases.

UIOBORN UTENNERS

2227 WHITE AVENUE, FRESNO, CALIFORNIA 


\section{Spratt's Dog Cakes}

Are known the world over for their nutritive qualities. Dogs fed on "Spratt's" thrive better, have finer coats and live longer. All the leading kennels use them.

We recently had two bitches with young litters, whose milk was not nourishing properly. We gave some of Spratt's Orphan Puppy Food to the mothers, morning and evening for a few days and the trouble was quickly removed.",

Hy-Born Kennels, Fresno, Cal.

Below is a partial list of Dog Foods manufactured by SPRATT'S PATENT:

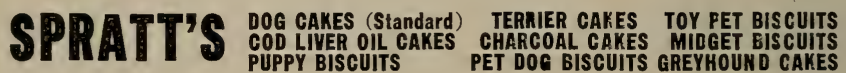

Spratt's Benching and Penning Outfits are fully equipped to care for all shows-both large and small. Secretaries are invited to write to us for prices.

Write for samples and send two cent stamp for "Dog Culture" which contains valuable information on the feeding, kenneling and general management of dogs.

\section{SPRATT'S PATENT, LTD.}

PACIFIC COAST BRANCH, 60 FEDERAL STREET, SAN FRANGISCO, CALIFORNIA

Newark, N. J. St. Louis, Mo. Cleveland, Ohio, Boston, Mass. Montreal, Canada. 




Nov 75

[IM] 
LIBRARY OF CONGRESS

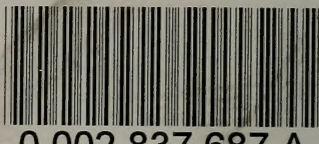

0002837687 A 